\title{
Microglia dynamics in adolescent traumatic brain injury
}

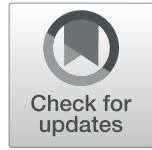

Eric Eyolfson ${ }^{1,2,3}$, Asher Khan ${ }^{2,3}$, Richelle Mychasiuk ${ }^{1,2,3,4}$ and Alexander W. Lohman ${ }^{2,3,5^{*}}$ (D)

\begin{abstract}
Repetitive, mild traumatic brain injuries (RmTBIs) are increasingly common in adolescents and encompass one of the largest neurological health concerns in the world. Adolescence is a critical period for brain development where RmTBls can substantially impact neurodevelopmental trajectories and life-long neurological health. Our current understanding of RmTBI pathophysiology suggests key roles for neuroinflammation in negatively regulating neural health and function. Microglia, the brain's resident immune population, play important roles in brain development by regulating neuronal number, and synapse formation and elimination. In response to injury, microglia activate to inflammatory phenotypes that may detract from these normal homeostatic, physiological, and developmental roles. To date, however, little is known regarding the impact of RmTBls on microglia function during adolescent brain development. This review details key concepts surrounding RmTBI pathophysiology, adolescent brain development, and microglia dynamics in the developing brain and in response to injury, in an effort to formulate a hypothesis on how the intersection of these processes may modify long-term trajectories.
\end{abstract}

Keywords: Synaptic pruning, Glia, Pathophysiology, White matter, Brain maturation, Complement cascade

\section{Background}

Traumatic brain injuries (TBI) can have devastating consequences on brain and mental health. Between Canada, the USA, and the European Union (EU), there are an estimated 46 million new TBI cases each year [1]. Among these, the vast majority $(\sim 80 \%)$ are classified as mild (mTBI) [2]. The highest age-specific rates for mTBI occurs in adolescents due to increased risk-taking behaviors and participation in contact sports [3], with sports-related mTBIs accounting for $60 \%$ of all adolescent cases [4]. Importantly, individuals who sustain a single mTBI are at high risk for acquiring repetitive mTBIs (RmTBI) [5]. While preventative measures to reduce injury rates are improving, the incidence of adolescent RmTBI continues to grow with no current therapies to improve outcomes [6].

\footnotetext{
*Correspondence: alex.lohman@ucalgary.ca

${ }^{2}$ Hotchkiss Brain Institute, University of Calgary, 3330 Hospital Drive NW Calgary, AB T2N4N1, Canada

${ }^{3}$ Alberta Children's Hospital Research Institute, University of Calgary, 3330 Hospital Drive, NW, Calgary, AB T2N4N1, Canada

Full list of author information is available at the end of the article
}

TBI pathophysiology encompasses primary and secondary injury cascades that collectively drive acute and chronic neurological damage and dysfunction. Defining the mechanisms of primary injury has been a major research focus, but the potential therapeutic window for intervention at this stage is limited, specifically in the case of mTBIs. This is because primary injury cascades initiate immediately following head trauma and unlike moderate-to-severe TBIs, diagnosis of mTBIs is often delayed. Therefore, concentrating research into the mechanisms controlling secondary injury cascades is an important step for developing strategies that aid recovery and improve the long-term neurological health in afflicted populations. A central component of secondary injury is neuroinflammation, a common process in a multitude of neuropathologies and neurodegenerative diseases [7-9]. Microglia, the brain's resident immune cell population, play important roles in both brain development and neuroinflammation that accompanies TBIs. Since adolescence is a critical neurodevelopmental

(c) The Author(s). 2020 Open Access This article is licensed under a Creative Commons Attribution 4.0 International License, which permits use, sharing, adaptation, distribution and reproduction in any medium or format, as long as you give appropriate credit to the original author(s) and the source, provide a link to the Creative Commons licence, and indicate if changes were made. The images or other third party material in this article are included in the article's Creative Commons licence, unless indicated otherwise in a credit line to the material. If material is not included in the article's Creative Commons licence and your intended use is not permitted by statutory regulation or exceeds the permitted use, you will need to obtain permission directly from the copyright holder. To view a copy of this licence, visit http://creativecommons.org/licenses/by/4.0/. The Creative Commons Public Domain Dedication waiver (http://creativecommons.org/publicdomain/zero/1.0/) applies to the data made available in this article, unless otherwise stated in a credit line to the data. 
period, neuroinflammation, and specifically microglial activation following injury, may have detrimental consequences on long-term quality-of-life and even invoke early onset of neuropsychological disorders [10-12]. However, to date, the majority of TBI research has focused on adulthood, limiting our understanding of injury mechanisms during adolescence, and specifically those mediated by microglia in post-injury neuroinflammation. This review highlights major concepts surrounding neuroinflammation in TBI, the current understanding of adolescent brain development, microglial function in the developing nervous system, and the integration of these disciplines. By examining differences in microglia activities between adolescence and adulthood, we introduce novel concepts related to how these cells may differentially impact secondary injury following TBIs and specific functions unique to the adolescent state.

\section{Traumatic brain injury}

TBIs are defined as insults to the brain caused by external forces resulting in acute or chronic neurological impairments. These injuries occur along a spectrum of severities (mild, moderate, and severe), pathologies, and clinical outcomes. Mild TBIs are among the most common in society ( $\sim 80 \%$ of all diagnosed cases) and are frequently caused by sports-related collisions, falls, motor vehicle accidents, and war zone blast injuries impacting military personnel $[13,14]$. They are typically characterized by a mechanical force delivered to the head, neck, or body that results in "coup" and "contrecoup" movements of the brain within the inside of the skull [15]. Len and Neary (2011) defined mTBI as a blow to the head and/or neck that causes rotational acceleration/deceleration of the brain, the onset of short-lived neurological deficits, potential loss of consciousness, and no skull fractures or macroscopic structural abnormalities assessed by neuroimaging. Mild TBIs are often classified as "concussions" in the clinical setting; however, not all mTBIs cause prototypical concussion [16]. Common neurological disturbances accompanying mTBIs range from acute symptoms including headache, nausea, dizziness, light/noise sensitivity, attention, concentration, and memory, to more long-term symptoms including irritability, sleep disturbances, anxiety, and depression [17-19]. When accounting for all acquired brain injuries, it appears that males experience more mTBIs than females with apparent sexually dimorphic symptomologies [20]. For example, when comparing male and female concussed soccer players, Covassin and colleagues found that females performed worse in visual memory tasks, had more total concussive symptoms (verbal and visual memory), and higher rates of migraine-induced cognitive fatigue and sleep disturbances up to 8 days post-injury [21]. Although most patients recover from post-injury symptoms within 7-10 days, a significant portion experience persistent symptoms that last for months, years, and in some cases for the remainder of their lives. These lingering symptoms have been termed post-concussive syndrome [22]. Moreover, individuals who acquire a single mTBI are at high risk for sustaining RmTBIs (due primarily to the nature in which the injuries are acquired) which can compound symptom severity and persistence [23]. RmTBIs are particularly relevant to individuals in sport and military environments where recurrent head collisions and blast injuries from explosions are frequently experienced. These individuals often return to play or duty (in the case of military personnel) before the brain has fully recovered, which can result in additive negative effects on long-term brain and mental health, and propel chronic neuropsychiatric disorders and neurodegenerative diseases [24, 25], such as mild cognitive impairment, Alzheimer's disease (AD), and related dementias, and Parkinson's disease (PD) [26, 27].

Adolescents have emerged as a prominent demographic for sustaining RmTBIs [28]. Remarkably, it is estimated that 1 -in- 6 youth experience a second injury within 2 years of their first [29]. Although males present more frequently with TBIs when accounting for all severities, among sex-comparable sports, adolescent females experience higher mTBI rates than males and often have worse symptomologies $[6,30]$, potentially due to differences in self-report [31]. To date, the majority of preclinical mTBI research has focused explicitly on adult injuries and neglected the female population [32]. While these studies have shed important light on pathophysiological mechanisms that dictate primary and secondary injury severity and the development of chronic neurological disorders, the specific, sexually dimorphic effects of RmTBI on adolescents, and the resulting impact on their acute and chronic neurological health remains largely unknown. Since adolescence is a critical neurodevelopmental period characterized by ongoing neuronal development, maturation, and fine-tuned circuit integration [33], RmTBIs sustained during this period may have severe consequences for life-long brain and mental health.

Immediately following a mTBI, the brain is thought to reside in a period of vulnerability where acquiring additional injuries can exacerbate neuropathology and accompanying neurological deficits. We currently do not know how long this window of enhanced vulnerability extends in humans, but preclinical RmTBI studies in rodents have demonstrated cumulative behavioral deficits and exacerbated neuropathophysiological hallmarks when administering consecutive injuries at varying time intervals. For example, Longhi and colleagues determined a critical time window for exacerbated behavioral deficits and neuronal dysfunction/damage when 
consecutive injuries occurred at 3-5-day intervals in adolescent male mice [34]. Subsequent studies have expanded this finding by altering RmTBI paradigms from multiple mTBIs per day for multiple days [35], to single mTBIs delivered every $24 \mathrm{~h}$ [36], $48 \mathrm{~h}$ [37], or $72 \mathrm{~h}$ [38]. Wright and colleagues directly compared the effects of a single mTBI or RmTBI in adolescent rats and noted cumulative effects of RmTBI on behavioral deficits, gene expression differences, and axonal integrity as compared to sham injuries with noted sex-differences [39]. Specifically, male rats exposed to RmTBIs had significantly worse deficits in short-term working memory whereas females displayed increased depressive-like symptoms. At the structural level, RmTBIs caused atrophy to the prefrontal cortex specifically in females whereas males had increased white matter tract damage in the corpus callosum [39]. To our knowledge, only one study has directly compared recovery from RmTBI in adolescent (post-natal day (P) 35) and adult mice (P120). While adult mice had reduced white matter volume compared to shams, no white matter changes were seen in adolescents following RmTBI. Despite the lack of gross anatomical changes, adolescent mice had prolonged behavioral deficits in motor and memory tasks up to 3 months post-injury [40]. This may suggest that secondary injury cascades accompanying TBI persist for days and even months following the initial injury, or that acute neuroinflammation causes chronic neurological changes, emphasizing the need to further characterize the temporal nature of cerebral vulnerability windows. In addition to these time-dependent effects, many environmental factors have been shown to influence the behavioral and molecular outcomes associated with RmTBI including sleep deprivation [41], diet (ketogenic diet: [42]; caffeine consumption [43]; monosodium glutamate (MSG) consumption [44]; alcohol consumption [45]), environmental enrichment [46], and exercise and anabolic steroid use [47]. Given the lack of knowledge surrounding cerebral vulnerability windows and the influence of various environmental factors on RmTBI pathophysiology during adolescence there is a significant need for future research in this area.

\section{TBI pathophysiology}

\section{Diffuse axonal injury}

Immediately following mTBI, primary injury cascades initiate that drive acute neurological deficits. Primary injury is caused by rotational acceleration and deceleration forces that cause differential velocities of white and grey matter (due to differing densities). The differential movement of white and grey matter imparts tensile and compressive strain to white matter tracts, which can sometimes result in shearing or tearing of axons. This is commonly referred to as diffuse axonal injury (DAI) (for reviews on DAI see $[48,49])$. DAI primarily occurs throughout white matter tracts within deep and subcortical brain regions like the corpus callosum [50]. This may reflect vulnerabilities of white matter tracts that are organized in parallel oriented bundles, making them more susceptible to the tensile strain associated with rotational acceleration and deceleration of the brain [49]. DAI is a major hallmark of all severities of TBI [50-52]. The brain is normally resilient to stretching and recovers to normal shape; however, during repetitive injuries the brain can lose these elastic capabilities exacerbating DAI pathology [53].

There are a number of pathophysiological hallmarks related to DAI (Fig. 1a). In the axon, shearing and tearing can drive aberrant influx of extracellular calcium causing neurofilament compaction, microtubule disassembly, interruption of axonal transport, the accumulation of transported organelles, and finally axonal swelling and axotomy [54-56]. While not characteristic of all time frames, axonal swelling is typically seen in the acute post-injury phase where axons can experience a 30 -fold increase in size from normal physiological conditions [56] leading to altered conduction velocities [57, 58]. Axons within a tract can also become misaligned due to cytoskeletal failure as a result of broken microtubules [56]. For example, in an in vitro model, stretching of axons caused microtubule breakage at the crests of axon undulations (smooth wave-like crests and troughs) [56]. At more chronic time points, axons are often shrunken, display axonal varicosities (swellings along the length of an axon), and formation of terminal axonal bulbs (singular axonal swelling resulting in complete axonal disconnection), common to Wallerian degeneration [56, 59, 60]. Collectively, these pathological changes to white matter tracts interrupt normal neurotransmission and negatively impact neural circuit dynamics. Moreover, axonal injury can spread over time further compromising healthy brain function. While the precise mechanisms driving the spread of injury are not clear, this phenomenon may be explained in part by the actions of secondary injury cascades.

\section{Secondary injury cascades}

The accelerative and decelerative forces experienced by cell membranes during TBI, combined with primary DAI pathology, can initiate secondary injury cascades that have additional negative effects on neuronal health and function (for in-depth reviews of secondary cascades, see $[61,62]$. Secondary injury cascades can initiate within minutes of injury and extend for months. They are characterized by dysregulated cerebral blood flow (CBF) [63], altered metabolic and cellular homeostasis, ionic dysregulation [64], mitochondrial dysfunction [65], neuronal atrophy, cell death, and neuroinflammation 

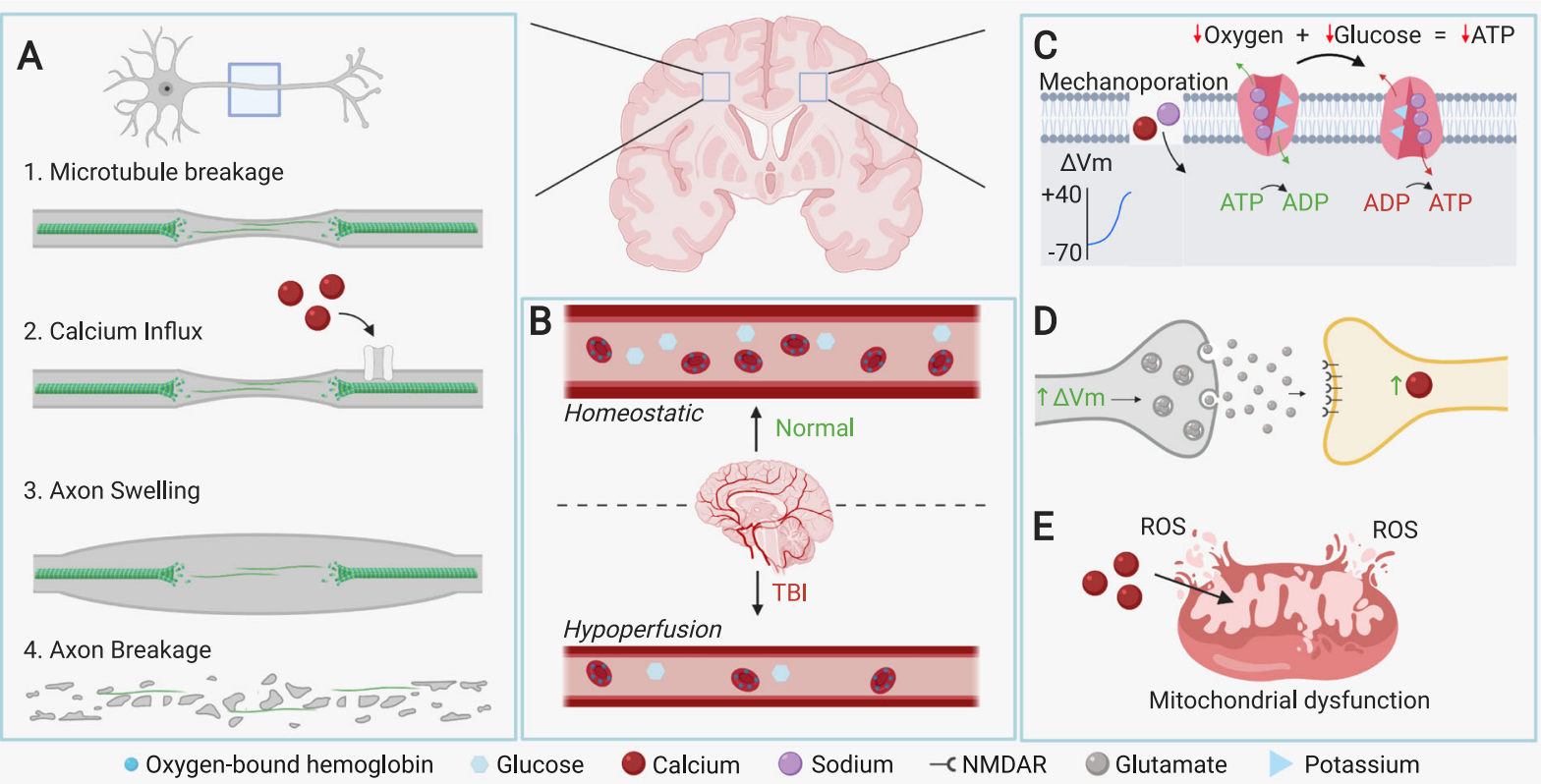

Fig. 1 Primary and secondary injury cascades following TBI. a Diffuse axonal injury that results from the differential velocities of white and grey matter during a traumatic impact induces tensile strain and microtubule damage within axons. This event induces accumulation of microtubule transport proteins/cargo and calcium influx, resulting in axonal swelling and ultimately axonal degeneration. b TBI reduces cerebral blood flow through impaired autoregulation and increased vasoconstriction, thereby reducing glucose and oxygen throughout the brain. c Axonal stretching induces mechanoporation, facilitating depolarization via the influx of sodium and calcium ions. Additionally, reductions in oxygen and glucose delivery reduce neuronal ATP levels causing failure or reversal of ATP-dependent ion transporters/pumps such as the sodium/potassium ATP pump. This further exacerbates ionic dysregulation by exporting potassium and importing sodium ions. $\mathbf{d}$ lonic imbalances which lead to depolarization of pre-synaptic neurons result in dysregulated glutamate release into the synaptic cleft, which over-activates NMDAR receptors and increases calcium influx into post-synaptic neurons (termed excitotoxicity). e Unregulated calcium influx drives neuronal death through mitochondrial dysfunction and the release of reactive oxygen species (ROS)

[66] (Fig. 1b). Detailing the entirety of secondary injury cascades following mTBI would be a tall task and reviews of this topic have been identified above. As it is important to have a broad understanding of the neural environment following injury, this review will touch on a few of the most important components of secondary injury cascades, before delving into an in-depth review of neuroinflammation (specifically microglial response) in Section 3.3.

In humans, mTBIs generally cause acute periods of reduced CBF up to 1 day post- injury [67], although CBF regulation is complex and may vary by age and injury severity. Cerebral hypoperfusion is primarily driven by impairments in cerebrovascular autoregulation (vascular constriction/dilation in response to changes in perfusion pressure to maintain constant blood flow) resulting in significant reductions in oxygen and energy substrate (e.g., glucose) delivery to the brain (Fig. 1b) $[16,68]$. Interestingly, human and rodent TBI studies have collectively reported acute hypermetabolism following brain injury followed by variable periods of hypometabolism depending on the severity of injury [69-72]. Prolonged reductions in oxygen and glucose transport to the brain, along with hypometabolism, depletes ATP stores that are vital for maintaining charge separation across neuronal membranes and efficient neurotransmission (Fig. 1c). In experimental rodent models of severe fluid percussion TBI, global reductions in CBF were observed as early as 15 min post-injury and recovered within 2-h [73]. In both human and rodent RmTBIs, alterations to CBF and metabolism are evident and vary depending on the mechanism and number of injuries [74-76]. For example, following murine RmTBI, decreased cortical CBF was observed accompanying microglia activation, in part due to the upregulation of cytokines such as RANTES, interleukin (IL)-13, IL-10, and IL-15 [77]. Combined with reductions in CBF, axonal stretching can induce mechanoporation and activate mechanosensitive ion channels, further exacerbating ionic imbalance across neuronal membranes perpetuating depolarization (Fig. 1c) [78]. Mechanoporation typically occurs in the acute phase following TBI and is characterized by the formation of small non-selective pores in the lipid membrane that allow ions to travel down their electrochemical gradients [78]. Collectively, the ionic imbalance in affected neurons can alter the surrounding neural environment causing secondary ionic disturbances in nearby uninjured neurons [79]. This membrane dysfunction can persist for several hours post-injury [79]. In response to reduced CBF and mechanoporation- 
dependent depolarization of neurons, aberrant neurotransmitter release ensues that can lead to excitotoxicity and neuronal death. In general, this is thought to be driven largely by overactivation of post-synaptic NMDA receptors in response to excessive glutamate release, pathological influx of $\mathrm{Ca}^{2+}$ ions, and subsequent mitochondrial dysfunction (Fig. 1c). Although our understanding of the molecular mechanisms driving these injury cascades has broadened, the precise timing of $\mathrm{CBF}$ alterations, cytotoxic ionic imbalances, and accompanying pathways driving neuronal death/ dysfunction have not been fully elucidated and appear to vary depending on the type and extent of injury. Notwithstanding, it is now clear that the immune system plays central roles in the regulation of primary and secondary injury cascades. Specific modulation of the post-traumatic neuroinflammatory response may therefore provide unique opportunities to limit the extent of neural dysregulation/ damage accompanying TBI and improve recovery.

\section{Neuroinflammation}

Pathophysiological signaling processes that accompany TBIs can initiate complex, dynamic neuroinflammatory responses that modulate both recovery and secondary injury cascades. Neuroinflammation is mediated by a number of different cell types including local glial cells (microglia, astrocytes), cerebrovascular endothelial cells, and peripheral immune cells (macrophages, neutrophils, T cells, B cells, etc.) [80].

Microglia are thought to be the first responders to injury. They detect alterations in their local environments by activating and synthesizing/secreting a plethora of signaling molecules that coordinate diverse effector functions such as phagocytosis of cellular debris and cytotoxic molecules, modulation of neuronal protein expression and activity, and orchestration of neural repair pathways [81]. Microglia are highly plastic cells, able to rapidly change along a spectrum of pro-inflammatory (M1-Like) and anti-inflammatory (M2-like) phenotypes on an "as need" basis [82-84]. Under normal homeostatic conditions, microglia primarily exist in a surveillance state, sampling the extracellular milieu on a constant basis through their motile, ramified processes. In response to tissue damage or infection, these cells are activated, retracting their processes and adopting amoeboid morphologies reminiscent of peripheral macrophages [85]. Activated microglia that adopt classical M1-like phenotypes primarily synthesize and release pro-inflammatory molecules including IL-1 $\beta$, IL-6, IL-12, and tumor necrosis factor $\alpha$ (TNF $\alpha$ ) cytokines and CCL2 and CXCLR9 chemokines [86]. These proinflammatory cytokines induce alterations in intracellular $\mathrm{Ca}^{2+}$ dynamics that can modify synaptic plasticity, neurotransmitter release, and neuronal excitability [87, 88]. Conversely, M2-like microglia are considered "alternative" activated states promoting anti-inflammatory profiles (induced by IL-4, IL-10, IL-13, and transforming growth factor- $\beta$ ) involved in resolution of neuroinflammation through increased phagocytic activity and tissue repair [89]. It is now clear that microglia are highly heterogeneous and can adopt a variety of phenotypes depending on changes to their immediate neural environments. As such, it is not surprising that these cells play dynamic roles in neuroinflammation, influencing both injury resolution/ tissue repair and further dysfunction/destruction.

Within the acute post-injury window, disruptions in neuronal membranes by mechanical forces and DAI cause release of damage-associated molecular patterns (DAMPs; e.g., ATP, HMGB1 and heat shock proteins) that can signal through receptor-dependent mechanisms to activate microglia, and alter inflammatory phenotypes and effector functions (Fig. 2) [90, 91]. In addition to these immediate responses, microglial-derived signaling molecules and DAMPs can modulate blood-brain barrier (BBB) function in the cerebral vasculature [90]. While the central nervous system (CNS) has historically been considered an immune-privileged organ due to this barrier and absence of classical antigen presenting cells, it is now well recognized that peripherally restricted immune cells can gain access to the brain parenchyma in cases of injury and/or infection [92, 93]. Like many other neuroimmunological diseases, TBIs can disrupt the BBB and permit the invasion of peripheral immune cells that play dynamic roles in the post-injury inflammatory profile (for review on mechanisms of BBB function/permeability in TBI see [94]).

In experimental models of $\mathrm{TBI}$, timing of $\mathrm{BBB}$ disruption often occurs in a biphasic manner and is dependent upon injury severity and the method of injury induction [95]. In models of moderate-to-severe TBI, BBB permeability has been observed immediately following injury $(\sim 2 \mathrm{~h})$ and persists for up to 7 days post-injury [63, 95]. Conversely, in $\mathrm{mTBI}$ and RmTBI, there is high variability in observable BBB disruption, with some studies reporting robust disruption and others reporting no observable changes [60, 63, 96-99]. Furthermore, diffuse injuries may result in sexually dimorphic responses whereby males are more prone to $\mathrm{BBB}$ disruption than females $[97,100]$.

Congruent with the dynamic nature of BBB permeability, the infiltration of peripheral immune cells appears to occur in a cell type-specific and time-dependent manner. Circulating neutrophils are among the first cells to infiltrate, usually within the first hour and peaking by $24 \mathrm{~h}$ post-injury, initiating enhanced inflammatory signals $[101,102]$. Monocyte-derived macrophages enter the CNS within $24 \mathrm{~h}$ of injury and peak at approximately 96 hours, readily crossing the $\mathrm{BBB}$ aided by neutrophils [103-105]. T cells and dendritic cells, peaking at $\sim 72 \mathrm{~h}$, have similar profiles to monocytes but in lower numbers 


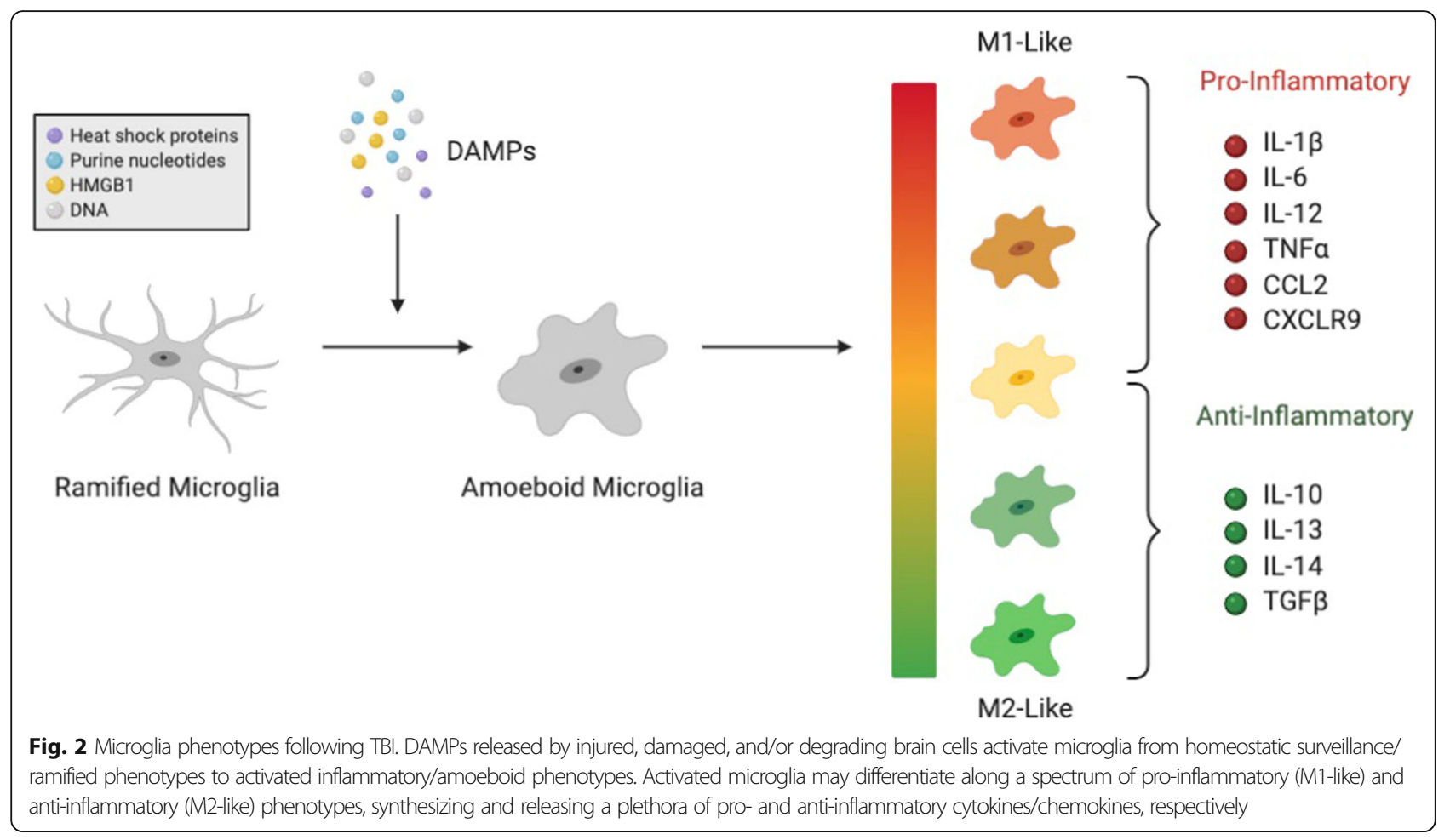

$[106,107]$. Together, the spatiotemporal dynamics of microglia, precise timing of peripheral immune cell infiltration, the identity and phenotypic polarization of these cells, and the coordinated signaling mechanisms they impart shape the neuroinflammatory environment and dictate dichotomous aspects of neural repair and secondary injury.

While we appreciate that the inflammatory response in TBI is complex and multifaceted, this review focuses on the differential roles for microglia in adolescent mTBIs. For in depth review of global neuroinflammatory dynamics in TBI see Simon et al., 2017 [108]. We believe that there are two key areas of research missing within the literature regarding the microglial inflammatory response following TBI. First, there is a lack of representation of the adolescent time period with most studies to date focusing on adulthood, and second, there is a gap in knowledge with respect to females, where the majority of studies have focused solely on males. Given known sex differences in microglial development and injury responses [109-111] along with age-specific effector functions, we believe that these cells play important, differential roles in neuroinflammation accompanying adolescent RmTBI.

\section{Adolescence}

Adolescence represents a critical developmental period between childhood and adulthood, generally categorized from 8 to 20 years of age in humans [112], 30 to 60 months in non-human primates [113], and 35 to 60 days in rodents [114]. This dynamic developmental period encompasses a multitude of changes including refinement of higher-order cognition [113], brain maturation [33], the onset of puberty [115], changes in social and risktaking behaviors [12], and onset of major disorders such as schizophrenia [10], substance-abuse [11], and mood disorders [116]. The start of adolescence is generally characterized by the onset of puberty (although adolescence and puberty are exclusive terms) [113]. Interestingly, the hormonal events associated with puberty influence brain maturation in females before males [117]. While sex hormones are responsible for sexually differentiating neural circuits during embryogenesis, during puberty, they activate reproductive behaviors and organize neural circuits [115].

\section{Adolescent brain development.}

Adolescent maturation is a complex process that culminates in novel and complex social and environmental interactions and experiences. Specifically, it represents a period of social autonomy, sensation-driven behavior, and sexual maturation [118]. Throughout adolescence the brain is extremely plastic and undergoes robust experience-dependent rewiring influenced by coordinated dendritic spine formation and elimination, and myelinogenesis [119, 120], (for review on adolescent brain development, see [121]). By adolescence, total brain volume is relatively stable and remains this way 
into adulthood. However, this does not explicitly imply that all brain regions undergo linear development. Grey matter (unmyelinated axons, dendrites) decreases during adolescence in a region-specific manner $[121,122]$. These grey matter changes appear to be dependent on significant region and sex-specific changes in synaptic pruning [123, 124]. Interestingly, testosterone has been positively correlated with grey matter volume whereas estradiol levels have been negatively associated [125]. In contrast to grey matter, white matter volume expands throughout adolescence in a sex-specific manner, whereby females demonstrate earlier developmental changes, but males appear to show steeper age-related increases [126, 127]. Given that adolescence is a critical period of learning, increased social autonomy, and complex social interactions [128], it is likely that white matter tract development is continually altered throughout this period. In both longitudinal and cross-sectional studies, fractional anisotropy (a measure of white matter integrity) exhibits both age and region-specific changes [129]. In one particular study, region-specific increases in fiber integrity were noted in all fiber tracts throughout the brain measured (arcuate, cingulum, fornix, genu, inferior fronto-occipital fasciculus, inferior longitudinal fasciculus, splenium, and uncinate) when examining adolescents between 9 and 12 years of age [129]. Importantly, microglia play important dynamic roles in the developing CNS and their dysregulation may have profound effects on the adolescent neurological state.

\section{Microglia and the developing CNS}

Microglia are among the most abundant and versatile glial cells in the CNS, encompassing 10-15\% of total glial cells [130]. While it has classically been thought that microglia primarily functioned in CNS immune responses and homeostasis, it is now known that they play central roles in shaping CNS development by promoting neuronal survival, inducing programmed neuronal death, and fine tuning synaptic connections through synaptogenesis and dendritic spine pruning [131, 132]. Dysregulation of microglial function has been implicated in a number of neurological disorders and pathologies including obsessive compulsive disorder [133], AD [134], PD [135], chronic traumatic encephalopathy (CTE) [136], and brain infections [137]. Microglial dysfunction has also been implicated in aging [138]. Aging-related dysregulation may impair microglia's ability to regulate homeostasis by altering the balance between surveillance and activated phenotypes along the M1-like/M2-like spectrum $[138,139]$. Given microglia play central roles in CNS development in utero and immediately following birth, it stands to reason they would also shape the CNS during other critical periods of neurodevelopment, including adolescence. This is especially relevant when considering the substantial white matter tract development in the prefrontal cortex (PFC) that occurs in this age group [122] [126]. Uncovering age-related differences in TBI pathophysiology and specific functions of microglia could therefore increase our understanding of the differential impact of sustaining these injuries during adolescence or adulthood.

\section{Microglia development}

Microglia are the first glial cells to colonize the CNS, however, unlike the neuroectodermal origin of most neural cells, microglia are derived from the yolk sac (for reviews, see [140]). The most conclusive evidence for this was determined by Ginhoux and colleagues (2010). During early embryogenesis, they populate the brain in an amoeboid morphology, which facilitates migration, and share many surface antigens and effector functions with peripheral blood-borne immune cell populations [141]. In rodents, amoeboid microglia transition towards a ramified morphology around embryonic day (E) 10.5 and complete ramification by P28 [142]. During this period, microglia are also proliferating. Microglial proliferation is a continual process beginning in the early postnatal days of murine life and reaching maximal concentration around two weeks of age [143]. By 18 weeks of age in humans, most microglia display ramified morphologies and have dispersed throughout the CNS [144]. These mature microglia display smaller cell bodies and longer, more ramified processes compared to immature microglia [145]. The transition from amoeboid to ramified morphologies appears to be dependent on the presence of other CNS resident cells, notably neurons and astrocytes [146-150].

Notwithstanding, there appear to be spatial differences in microglia morphology. For example, in subcortical white matter microglia display more amoeboid morphologies, whereas cortical microglia display diffuse distribution and ramified morphologies [131]. During development, microglia in murine models form hotspots and cluster in white-matter tracts with distinct spatiotemporal patterns of distribution and expression of different cellular markers [81] [141, 144]. The clustering on white-matter tracts suggests microglia play an important role in axonal growth, guidance, and myelination [141]. Indeed, through regulation by cytokines and chemokines (i.e. IL-34, CXCL12, and CX3CL1), microglia promote axonal outgrowth in regions such as the corpus callosum $[151,152]$. Throughout adulthood, microglia exhibit longevity independent of replenishment by bone marrowderived progenitors, owing to their ability to undergo self-renewal [153]. Transplants from bone marrow derived myeloid cells reconstituted less than $10-20 \%$ of total microglial cells, indicating that once microglia enter the CNS they are self-renewing and do not re-infiltrate 
from the periphery [142]. Self-replication means microglial density remains fairly consistent throughout life, although there are region-specific and pathological turnover rates [154].

Recently, sex differences in microglial morphology, maturation, and function have come to light. In the early postnatal period, males exhibit region-specific (amygdala, hippocampus, nucleus accumbens, preoptic area) increases in microglia number, while at the beginning of adolescence (P30), females have more microglia in those brain regions [110, 155]. Production of testosterone by testes in the late gestation period may drive the early microglial increases in males since ovaries are largely silent at this time [155]. Once colonization is established, microglia contribute directly to many facets of brain development and sexual differentiation.

\section{Microglial effector functions in the developing CNS}

Microglia are key contributors to normal CNS development and function, providing important multifaceted effector functions that shape the CNS throughout life. The precise timing of microglia emergence in the CNS corresponds with the birth of neurons [131, 152]. Accordingly, in the prenatal and perinatal brain, microglia regulate neurogenesis and maturation of developing neurons by controlling the balance between neuronal death and survival, phagocytosing neuronal progenitors, coordinating axonal outgrowth, and promoting neuronal fasciculation [156-158]. During embryogenesis, microglia regulate neurogenesis at the terminal stage of cortical development by phagocytosing progenitor cells in the ventricular and subventricular zones [152]. Support for this function was determined by pharmacologically depleting microglia, which resulted in an increase in progenitor cell number. Conversely, activation of microglia from their ramified, homeostatic state by maternal immune activation (injection of lipopolysaccharide) caused a decrease in neural progenitors [152]. This neurogenic role does not conclude in utero, but continues throughout the post-natal period regulating neural development in the subventricular zone of the developing cerebral cortex [152]. During development microglia also play dual roles that control differentiated neuronal survival and elimination. Over half of the neurons present at birth are eliminated. Microglia directly regulate survival by releasing trophic factors (i.e., insulin-like growth factor-1 promoting the survival of layer $\mathrm{V}$ neurons) [131] and eliminate specific neurons undergoing programmed cell death via coordinated microgliadependent phagocytosis [159].

In the post-natal brain microglia modulate synapse number, maturation, and survival, all of which collectively influence neuronal activity [160]. Most notably, recent discoveries have highlighted microglia as direct regulators of synaptic pruning [132, 160, 161]. Throughout normal development, neurons create excess synaptic connections, and it is the role of ramified microglia to prune unnecessary connections and strengthen remaining synapses [160]. Removal of excess synapses is vitally important for the development of proper neuronal connections and the integration of higher-order circuits that control healthy CNS function [162-164]. To date, microglial-dependent synaptic pruning has been observed in numerous brain regions such as thalamus, cerebellum, olfactory bulb, and hippocampus (HPC) [165]. The functioning of microglia in synaptic pruning during development is highly responsive to experience $[166,167]$. Evidence for microglial experience-dependent synaptic pruning comes from experiments in the developing visual cortex [132]. In short, Tremblay and colleagues found that under normal development microglia clustered around growing dendritic spines and were in direct contact with synaptic clefts. In response to altered sensory experience (light deprivation) and re-exposure, microglia were less motile, increased phagocytosis of synaptic elements, and localized to larger dendritic spines [132]. This experience-dependent synaptic pruning implicates microglia in synaptic remodeling.

But how do microglia determine which synapses to prune? Recently, the complement system has been implicated in regulation of microglial-dependent synaptic pruning (Fig. 3). The complement system comprises a series of proteins, $\mathrm{C} 1$-to- $\mathrm{C} 9$, that are part of the innate immune system with roles in cytokine production, vascular permeability, recruitment of macrophages, and opsonization (for review, see [168]). The specific complement proteins $\mathrm{C} 1 \mathrm{q}, \mathrm{C} 3$, and $\mathrm{C} 4$ have been directly linked to synapse engulfment [169]. Microglia express receptors for C1q (C1qR) and C3 (C3R or CD11b) [170] that coordinate the mechanisms for selective engulfment of pre- or post-synaptic terminals. First, microglia recognize $\mathrm{C} 1 \mathrm{q}$ tagged on post-synaptic dendrites (through their $\mathrm{C} 1 \mathrm{qR}$ ) to initiate phagocytosis of this structure. Second, neuronal upregulation of C1q cleaves C3 into C3b which is displayed on pre-synaptic elements for targeted phagocytosis [170]. Knocking out C1q results in deficits in synaptic pruning causing excessive innervation of lateral geniculate nucleus neurons [169]. Tagging of pre- and post-synaptic elements by specific complement proteins is thought to be regulated by activity. It has been proposed that less active (weaker) synapses are selectively tagged with complement components to signal their engulfment and strengthen remaining connections. Alternatively, it is possible that all synapses express complement components but some also harbor complement regulatory proteins that prevent recognition by microglia $[171,172]$. Nonetheless, it is clear that synaptic pruning through the complement system is tightly 


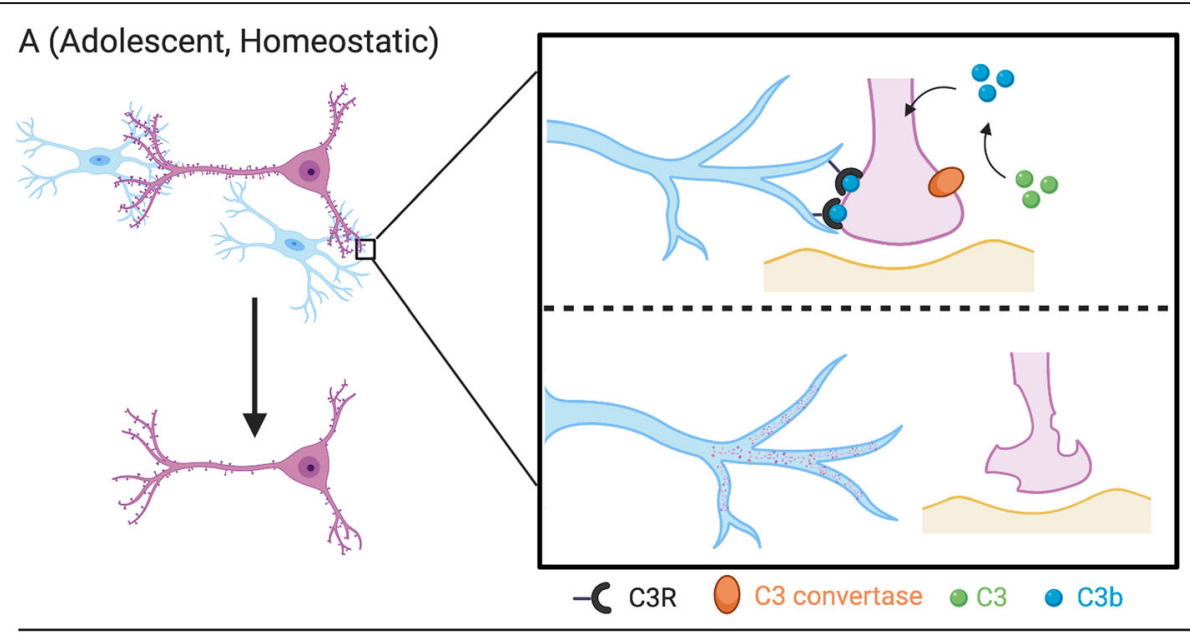

B (Adolescent, RmTBI)

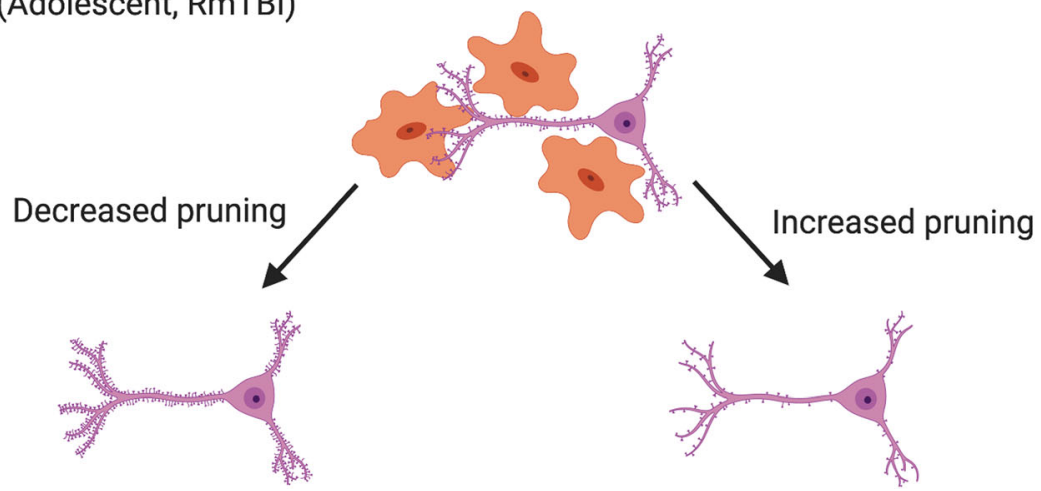

Fig. 3 Complement-mediated synaptic pruning by microglia in the homeostatic and RmTBl adolescent brain. a Under homeostatic conditions, the complement protein C3 is converted to C3b by C3 convertase which tags unnecessary or weak synapses for pruning. Microglia, which highly express the C3 receptor (C3R), bind to synaptically tagged C3 molecules facilitating microglia-mediated pruning of pre-synaptic terminals. b Following RmTBl, microglia-mediated synaptic pruning may be either increased or decreased compared to homeostatic conditions. Ramified microglia are thought to be more efficient at synaptic pruning compared to amoeboid microglia, which could reduce pruning during adolescence. Alternatively, increased expression of C3 following RmTBI may facilitate increased synaptic pruning by activated/amoeboid microglia. Collectively, alterations in synaptic pruning caused by RmTBls may directly influence synaptic density and overarching neural development and health

regulated and likely restricted to key developmental stages [109, 169]. However, Hong and associates determined that in rodent models of $\mathrm{AD}, \mathrm{C} 1 \mathrm{q}$, and $\mathrm{C} 3$ are expressed on synapses before $\beta$-amyloid plaque formation and associated synaptic loss, while blockade of the complement cascade in this system protected against synaptic loss [173]. This observation may suggest that complement-mediated synaptic pruning by microglia drives the early synaptic and cognitive impairments that often precede overt plaque formation in $\mathrm{AD}$. To date, the majority of studies on complement-mediated synaptic pruning by microglia have focused on early developmental periods, but an important recent study extended these observations into the adolescent stage. Kopec and colleagues determined that $\mathrm{C} 3$ and microglial C3R mediated synaptic pruning in dopaminergic neurons in the nucleus accumbens of adolescent male rats [174]. Interestingly, synaptic pruning in females was not mediated by $\mathrm{C} 3$ and microglial C3R. When C3-C3R interactions were pharmacologically blocked, microglia exhibited decreased phagocytic activity resulting in increased rodent social play behavior in a sexually dimorphic manner.

\section{Age- and sex-dependent microglia dynamics in TBI pathophysiology}

The dual role of microglia in neuroinflammation

Microglia-dependent inflammatory processes in TBI are evident in both focal and diffuse injuries (for review, see [108]). As a result of neuronal membrane damage/disruption, released DAMPs activate microglia, causing proliferation and migration to sites of injury in an effort to "wall off" damaged neurons, phagocytose cellular debris, and clear cytotoxic molecules from the extracellular milieu [175, 187]. The heterogeneous effects of mTBI and RmTBI on microglial reactivity are summarized in Table 1 . Nonetheless, it is generally accepted that while 
Table 1 Microglia activation following TBI

\begin{tabular}{|c|c|c|c|c|c|c|c|}
\hline Reference & $\begin{array}{l}\text { Strain/ } \\
\text { sex/age }\end{array}$ & Model (severity) & $\begin{array}{l}\text { \# of } \\
\text { impacts/ } \\
\text { ICI }\end{array}$ & $\begin{array}{l}\text { Microglia } \\
\text { marker }\end{array}$ & Time PI & Regions & Findings \\
\hline \multirow[t]{2}{*}{ [37] } & \multirow[t]{2}{*}{$\begin{array}{l}\text { C57/ } \\
\text { male/9-15 } \\
\text { months }\end{array}$} & \multirow[t]{2}{*}{ Controlled impact } & $5 / 48 \mathrm{~h}$ & lba1 & $\begin{array}{l}6 \text { months, } \\
12 \text { months }\end{array}$ & $\begin{array}{l}\text { Cortex } \\
\text { (retrosplenial, } \\
\text { sensormotor, } \\
\text { motor), CC, CA1, } \\
\text { DG }\end{array}$ & $\begin{array}{l}\text { Cortex: no difference at } 6 \text { or } 12 \text { months; } \\
\text { CC: Increase at } 6 \text { months and } 12 \\
\text { months; CA1and DG: no change }\end{array}$ \\
\hline & & & 1 & lba1 & $\begin{array}{l}6 \text { months, } \\
12 \text { months }\end{array}$ & $\begin{array}{l}\text { Cortex } \\
\text { (retrosplenial, } \\
\text { sensorimotor, } \\
\text { motor), CC, CA1, } \\
\text { DG }\end{array}$ & $\begin{array}{l}\text { Cortex: no difference; CC: Increase at } 12 \\
\text { months; CA1 and DG: no difference }\end{array}$ \\
\hline [38] & $\begin{array}{l}\text { Sprague- } \\
\text { Dawley/ } \\
\text { male and } \\
\text { female/ } \\
\text { P30 }\end{array}$ & Lateral impact & $3 / 3$ days & lba1 & 16 days & VMH & Increase following RmTBI in males only \\
\hline \multirow[t]{2}{*}{ [40] } & $\begin{array}{l}\text { C57/ } \\
\text { male/P35 }\end{array}$ & Mod. weight drop & $7 / 9$ days & |bal & 3 months & CA1 & \multirow[t]{2}{*}{$\begin{array}{l}\text { Increase in both ages with no } \\
\text { difference in adolescent's vs adults }\end{array}$} \\
\hline & $\begin{array}{l}\text { C57/ } \\
\text { male/ } \\
\text { P120 }\end{array}$ & Mod. weight drop & $7 / 9$ days & lba1 & 3 months & CA1 & \\
\hline \multirow[t]{2}{*}{ [98] } & \multirow[t]{2}{*}{ C57 } & \multirow{2}{*}{$\begin{array}{l}\text { Mahmood weight } \\
\text { drop }\end{array}$} & $5 / 24 \mathrm{~h}$ & Isolectin B4 & 30 days & HPC & No activation \\
\hline & & & $10 / 24 h$ & Isolectin B4 & 30 days & $\mathrm{HPC}$ & No activation \\
\hline \multirow[t]{2}{*}{ [175] } & \multirow[t]{2}{*}{$\begin{array}{l}\text { Long- } \\
\text { Evans/ } \\
\text { male/ } \\
\text { adult }\end{array}$} & \multirow[t]{2}{*}{ mLFP } & \multirow[t]{2}{*}{1} & \multirow[t]{2}{*}{ CD68 } & 4 days & $\begin{array}{l}\text { Ips and Con } \\
\text { perirhinal } \\
\text { cortex, parietal } \\
\text { cortex, temporal } \\
\text { cortex }\end{array}$ & Increased expression in all regions \\
\hline & & & & & 32 days & $\begin{array}{l}\text { Ips and Con } \\
\text { perirhinal } \\
\text { cortex, parietal } \\
\text { cortex, temporal } \\
\text { cortex }\end{array}$ & No differences \\
\hline [176] & $\begin{array}{l}\text { C57/ } \\
\text { male/ } \\
\text { P120-150 }\end{array}$ & Mod. CCl & $\begin{array}{l}30 / \\
5 \text { on } 2 \\
\text { off }\end{array}$ & Iba1, CD68 & $\begin{array}{l}1 \text { day, } 60 \\
\text { days, } 365 \\
\text { days }\end{array}$ & $\begin{array}{l}\text { Optic Tract and } \\
\text { LGN }\end{array}$ & Elevated at all time points \\
\hline [177] & $\begin{array}{l}\text { C57/ } \\
\text { male/P84 }\end{array}$ & Mod. CCl & $\begin{array}{l}42 / \\
6 \mathrm{per} \\
\text { day/2h }\end{array}$ & CD68 & $\begin{array}{l}7 \text { days, } 1 \\
\text { month, } 6 \\
\text { months }\end{array}$ & $\begin{array}{l}\text { Cortex, Amy, } \\
\text { DG, CA1, CA3 }\end{array}$ & $\begin{array}{l}7 \text { days: Increase in cortex, con amy, } \\
\text { CA3; } 1 \text { month: increase ips cortex, ips } \\
\text { amy, ips/con DG; } 6 \text { months: Increase } \\
\text { ips/con cortex, ips/con amy, ips/con } \\
\text { DG, ips/con CA1, ips/con CA3 }\end{array}$ \\
\hline [178] & $\begin{array}{l}\text { C57/ } \\
\text { male/ } \\
\text { P60-90 }\end{array}$ & Mod. CCl & $2 / 24 \mathrm{~h}$ & |ba1 & $\begin{array}{l}2 \text { days, } 4 \\
\text { days, } 7 \text { days, } \\
14 \text { days, } 28 \\
\text { days, } 49 \\
\text { days }\end{array}$ & $\begin{array}{l}\text { Ips cortex, Ips } \\
\text { DG, CC, Ips } \\
\text { Thalamus }\end{array}$ & $\begin{array}{l}\text { Ips cortex: Increase 4/7/14/28d; Ips } \\
\text { thalamus: Increase } 4 / 7 / 14 / 28 \text { days; CC: } \\
\text { Increase 4/7/14/28/49 days; Ips DG: } \\
\text { Increase 2/4/7 days; Con CA: Increase } 4 \\
\text { days }\end{array}$ \\
\hline \multirow[t]{2}{*}{ [179] } & \multirow[t]{2}{*}{$\begin{array}{l}\text { C57/ } \\
\text { male/P70 }\end{array}$} & \multirow[t]{2}{*}{ Controlled impact } & 1 & |ba1 & $\begin{array}{l}24 h, 10 \\
\text { days }\end{array}$ & $\begin{array}{l}\text { Cortex, CC, } \\
\text { brainstem }\end{array}$ & $\begin{array}{l}\text { Cortex: no difference; CC: moderate } \\
\text { both times; CA1: present both times; } \\
\text { brainstem: no difference }\end{array}$ \\
\hline & & & $5 / 48 \mathrm{~h}$ & |ba1 & $24 \mathrm{~h}$ & & $\begin{array}{l}\text { Cortex: moderate increase; CC: intense } \\
\text { increase; brainstem: no difference }\end{array}$ \\
\hline [180] & $\begin{array}{l}\mathrm{BALB} / \mathrm{c} / \\
\mathrm{male} / \mathrm{P} 90\end{array}$ & $\begin{array}{l}\text { Midline diffuse FPI } \\
\text { (moderate) }\end{array}$ & 1 & $\begin{array}{l}\text { Flow: CD14; } \\
\text { Immuno: Iba1 }\end{array}$ & $\begin{array}{l}\text { Flow: } 4 \text { h, } 72 \\
\text { h; Immuno: } \\
30 \text { days }\end{array}$ & $\begin{array}{l}\text { Flow: Cortex, } \\
\text { HPC; Iba1: DG, } \\
\text { PCX, PFC; }\end{array}$ & $\begin{array}{l}\text { Flow: CD14 microglia increases at } 4 \text { and } \\
\text { 72; lba1: } 30 \text { days increase in DG and } \\
\text { PCX but not PFC }\end{array}$ \\
\hline [181] & $\begin{array}{l}\text { Wistar/ } \\
\text { female/ } \\
\text { P56 }\end{array}$ & $\begin{array}{l}\mathrm{CCl} \\
\text { (moderate-to-severe) }\end{array}$ & 1 & $\begin{array}{l}\text { Flow: CD40, } \\
\text { CD68, CD163; } \\
\text { Immuno: CD68, } \\
\text { C163, CD68, } \\
\text { Iba1 }\end{array}$ & $\begin{array}{l}1 \text { day, } 3 \\
\text { days, } 5 \text { days, } \\
7 \text { days, } 14 \\
\text { days, } 30 \\
\text { days }\end{array}$ & Cortex & $\begin{array}{l}\text { Flow: CD163 increase } 3 \text { days and } 5 \\
\text { days; CD40 and CD68 no difference } \\
\text { Immuno: CD68: increase at 5/7/14 days; } \\
\text { Cd163: Increase } 5 \text { and } 7 \text { days; CD68: No } \\
\text { difference; Iba1: Increase } 7 \text { days }\end{array}$ \\
\hline
\end{tabular}


Table 1 Microglia activation following TBI (Continued)

\begin{tabular}{|c|c|c|c|c|c|c|c|}
\hline Reference & $\begin{array}{l}\text { Strain/ } \\
\text { sex/age }\end{array}$ & Model (severity) & $\begin{array}{l}\text { \# of } \\
\text { impacts/ } \\
\text { ICI }\end{array}$ & $\begin{array}{l}\text { Microglia } \\
\text { marker }\end{array}$ & Time PI & Regions & Findings \\
\hline [182] & $\begin{array}{l}\text { C57/ } \\
\text { male/ } \\
\text { P120-150 }\end{array}$ & $\begin{array}{l}\text { Closed-headed } \\
\text { impact model of } \\
\text { engineered } \\
\text { rotational } \\
\text { acceleration (CHIM } \\
\text { ERA) }\end{array}$ & 1 & Iba1 & $\begin{array}{l}6 \text { h, } 1 \text { day, } 2 \\
\text { days, } 7 \text { days, } \\
14 \text { days }\end{array}$ & $\begin{array}{l}\text { Optic tract, } \\
\text { olfactory nerve, } \\
\text { CC, brachium } \\
\text { sup. Colliculus }\end{array}$ & $\begin{array}{l}\text { Optic tract: increase } 2 / 7 / 14 \text { days; } \\
\text { olfactory nerve: increase } 1 / 2 / 7 / 14 \text { days, } \\
\text { CC: increase } 2 / 7 / 14 \text { days; Brachium: } \\
\text { increase } 2 / 7 / 14 \text { days }\end{array}$ \\
\hline \multirow[t]{2}{*}{ [183] } & \multirow{2}{*}{$\begin{array}{l}\text { Long- } \\
\text { Evans/ } \\
\text { male/ } \\
\text { young } \\
\text { adult }\end{array}$} & \multirow[t]{2}{*}{ LFP } & \multirow{2}{*}{$\begin{array}{l}1,3,5 / 5 \\
\text { days }\end{array}$} & \multirow[t]{2}{*}{ ED1 } & $24 \mathrm{~h}$ & Injured cortex & Increase following 3 and 5 injuries \\
\hline & & & & & 8 weeks & Injured Cortex & Increase following 5 injuries \\
\hline [184] & $\begin{array}{l}\text { C57/ } \\
\text { male/P60 }\end{array}$ & Mod. weight drop & $7 / 9$ days & Iba1, CD68 & 24 h, 7 days & $\begin{array}{l}\text { Fimbria white } \\
\text { matter and CA1 }\end{array}$ & $\begin{array}{l}\text { Increase in Iba1 and CD68 at } 24 \mathrm{~h} \text { and } \\
7 \text { days in both regions }\end{array}$ \\
\hline [185] & $\begin{array}{l}\text { C57/ } \\
\text { male/ } \\
\text { P60-90 }\end{array}$ & Mod. weight drop & $7 / 9$ days & lba1 & 3 months & $\begin{array}{l}\text { Fimbria white } \\
\text { matter and CA1 }\end{array}$ & Increase in both regions \\
\hline \multirow[t]{2}{*}{ [186] } & \multirow[t]{2}{*}{$\begin{array}{l}\text { Sprague- } \\
\text { Dawley/ } \\
\text { male/P18 }\end{array}$} & \multirow[t]{2}{*}{ Mod. CCl } & 1 & lba1 & 7 days & $\begin{array}{l}\text { Cortex, external } \\
\text { capsule, } \\
\text { amygdala }\end{array}$ & No difference \\
\hline & & & $2 / 1$ day & Iba1 & 7 days & $\begin{array}{l}\text { Cortex, external } \\
\text { capsule, } \\
\text { amygdala }\end{array}$ & No difference \\
\hline
\end{tabular}

Abbreviations: Amy amygdala, Con contralateral, CC corpus callosum, DG dentate gyrus, HPC hippocampus, ICI inter-injury interval, Ips ipsilateral, LGN lateral geniculate nucleus, LFP lateral fluid percussion, Mod modified, $P C X$ parietal cortex, PFC prefrontal cortex, VMH ventromedial hypothalamus

the acute microglial response has neuroprotective effects [108], when these cells reside in chronically activated states, they contribute to the window of cerebral vulnerability and compound the negative effects of repetitive injuries on neurological health.

\section{Chronic neuroinflammation and microglial priming}

Given the known homeostatic function of microglia in white matter tract development and synaptic organization, RmTBI-induced alterations to adolescent microglia may shift these cells to activated inflammatory states limiting their homeostatic role in normal development [81, 161]. Microglia can be chronically activated well after functional recovery from primary injuries, residing in a "primed" state that may exacerbate inflammatory responses with subsequent injuries or inflammatory stimuli $[188,189]$. In the context of mTBI and the associated risk of sustaining RmTBIs, the priming of activated microglia is an important consideration for translation of preclinical studies to the clinical setting [175]. As mentioned previously, the precise recovery window following TBI appears to vary with age, injury severity, and other genetic and environmental factors. Intriguingly, microglial priming places these cells in sensitized states where successive mTBIs promote detrimental inflammatory functions. In support of this, experimental priming of microglia with lipopolysaccharide (LPS), which activates microglia through toll-like receptor (TLR) signaling, significantly increased the number of activated microglia for up to 28 days following RmTBI, compared to single injuries or sham controls [190]. Similarly, LPS priming of microglia 5 days following single mTBI compounded behavioral deficits (increasing depressive-like symptoms and impairing cognition) and exaggerated pro-inflammatory microglia phenotypes up to 3 months following injury [191]. Furthermore, microglia priming is exacerbated by increasing concentrations of IL- $1 \beta$ and TNF $\alpha$, known endogenous signaling molecules elevated in the post-traumatic brain [180]. This priming effect may be best exemplified in the context of aging.

Microglia slowly transition from ramified surveillance states to activated phenotypes and increase in density throughout aging $[192,193]$. Aging microglia also appear to lose the ability to transition between surveillance and activated states and tend to reside in more activated phenotypes as aging progresses [194]. In the preclinical setting, Kumar and colleagues utilized a controlled cortical impact (CCI) model of mTBI in adult (3 months) and aged (24 months) mice, identifying increases in M1like and M2a-like microglial phenotypic markers and the presence of bushy/amoeboid microglia in the HPC, cortex, and thalamus of aged animals $24 \mathrm{~h}$ post-injury as compared to adult cohorts [195]. Prior work by Sandhir and colleagues reported that aged mice subjected to single CCI displayed increased Iba1 and CD11b mRNA and protein levels up to 3 days post-injury in the HPC, with a prolonged return to baseline as compared to adult 
mice [194]. Moreover, a complementary study utilizing a CCI model of RmTBI in aged mice revealed significant increases in Iba1 reactive microglia in the corpus callosum (but not HPC or cortex) 6 months post-injury which persisted for up to 12 months [37]. Consistent with these experimental studies, human patients with severe TBI may exhibit continued axonal degeneration and chronic microglia activation up to 18 years post-injury [196, 197]. Chronic microglial activation has also been reported in impact sport athletes following retirement suggesting that this phenomenon is not restricted to severe TBI, but also a hallmark of RmTBIs [198]. Collectively, both preclinical and clinical studies support the idea that microglia not only participate in acute inflammatory responses following brain injury, but can adopt primed, activated phenotypes that persist chronically and may play central roles in the pathophysiology accompanying cumulative TBIs. However, the characteristics of microglia activation in adolescent mTBI remain largely unknown and to our knowledge there have been no studies examining the impact of altered microglia dynamics during adolescent RmTBIs on adult outcomes.

\section{Microglia responses in adolescent TBI}

Current literature regarding microglia-dependent inflammatory responses in adolescent RmTBI is sparse and requires further investigation. However, in a model of pediatric (P18) RmTBI, researchers identified more amoeboid microglia in the cortex, HPC, and amygdala with single or RmTBI on post-injury day 7. However, no differences were noted in total quantity of Iba1 positive microglia when compared to sham rats on post injury days 7,21 , or 92 [186]. These observations suggest that single and RmTBI caused microglia activation with no overt gliosis. Similar to the findings by Fidan, Wu and colleagues saw no differences in Ibal expression in the cortex, corpus callosum, or hippocampus, $4 \mathrm{~h}$ and up to 1 year, between RmTBI and sham animals [199], which corroborates findings from adult research. It is important to note that while Iba1 is commonly used to identify microglia, it is also expressed by peripheral macrophages and may not be an ideal marker for microglia in injury models that cause BBB permeability and infiltration of peripheral cells. Juvenile (P21) mTBI induced regionand sex-dependent differences in microglial responses, whereby, males experienced higher activation of microglia compared to females, especially in regions affected by DAI [200]. Mannix and colleagues utilized a modified weight drop model of RmTBI to compare microgliadependent outcomes in adolescent (P35) or adult (P120) wild-type $\mathrm{C} 57 \mathrm{Bl} / 6$ mice. To our knowledge, this was the first closed-headed RmTBI model to directly compare adolescence and adult subjects. Adolescents exposed to RmTBI displayed similar magnitudes of gliosis to adults with RmTBI [40]. However, they did not monitor adolescent development following RmTBI into adulthood to determine long-term behavioral deficits or microglial reactivity. Given significant brain maturation is occurring during adolescence and the role microglia plays in synaptic pruning and overarching spine density, it is possible that RmTBI may alter normal neural development. While not directly analyzing microglial involvement, a number of studies have displayed increased spine density following adolescent RmTBI [43, 201-203]. Reductions in synaptic pruning may result from altered microglial functioning. Chronically activated microglia following RmTBI may be improperly regulating (or inhibiting) homeostatic functioning, leading to decreased synaptic pruning and increased spine density. It is known that alterations in synaptic density are hallmarks of a number of neuropsychiatric disorders. It will be key to determine how RmTBI received during key developmental periods affect susceptibility to neuropsychiatric disorders.

\section{Perspectives and conclusions}

As we have mentioned above, the adolescent developmental period is a critical time in life that is characterized by increased risk-taking behaviors and increased risk for mTBI. Yet, adolescents are severely underrepresented in the mTBI literature. We believe the adolescent period is important for future research for a number of reasons. First, during adolescence, white matter tracts are not fully developed. As we have mentioned, in DAI white matter tracts are especially susceptible to axonal sheering and tearing. Does this mean adolescents will experience more severe injuries because the tracts have less tensile strength? Or will they be less likely to display white matter injuries? It is possible adolescents will be more vulnerable to this type of injury as they have increased water content in the brain and may be more disposed to cerebral edema [204]. This claim is supported by Cernak and colleagues utilizing a pediatric model of mTBI in Sprague-Dawley rats. Following a single injury temporal patterns of edema in the cortex and hippocampus differed in juvenile (P7, P14, P21) and adult animals whereby, juveniles displayed edema formation earlier than adults [205]. Given the immense changes to brain structure during adolescence, temporal profiles may not follow the same trajectory as pediatric injuries. Indeed, a single injury at P30 did not cause identifiable edema in adolescent mTBI. However, administration of a second injury exacerbated secondary cascades and increased edema [206].

The findings from Mannix (2017) provide important support for this concept: adolescents exposed to RmTBI displayed similar magnitudes of microgliosis to adults with RmTBI [40]. While this may seem unimportant, chronic microgliosis following RmTBI is associated with 
persistent behavioral differences in adult models [185]. While beyond the scope of this review, it is also important to note that astrocytes play important immune related roles following brain injuries, and chronic astrocytosis may additionally compound behavioral deficits (for in-depth reviews, see [207, 208]). Importantly, microglia and astrocytes are known to engage in cross talk whereby, activation of one, also activates the other, suggesting that both play vital roles in the pathophysiology and recovery from injury [209]. In addition, we have highlighted specific roles for microglia in synaptic pruning in this review and recent evidence suggests that astrocytes may also play roles in synaptic pruning [210]. The injury-induced activation of microglia during adolescence may disrupt homeostatic synaptic pruning and lead to decreased dendritic branching similar to what has been identified in the ageing or AD brain $[173,211]$. Furthermore, both adolescence and TBI upregulate the complement cascade. Complement cascade expression is downregulated during non-developmental periods and is upregulated during adolescence. Kopec and associates confirmed that during adolescence, microglial-induced synaptic phagocytosis was mediated by protein C3 [109].
Further, C3 mRNA was significantly increased following experimental TBI [212]. Following RmTBI in adolescence, this upregulation of the complement cascade may mediate abnormal microglial synaptic pruning at otherwise strong, healthy synapses (Fig. 3) [164].

Finally, adolescent RmTBI may perpetuate abnormal microglia priming, reminiscent of aging where microglia lose the ability to shift from activated to ramified phenotypes. This is relevant because activated microglia are less capable of performing their homeostatic developmental functions. Studies have shown that microglial activation can persist up to 18 years following TBI in clinical populations [197]. It is therefore possible that adolescent RmTBI primes microglia to activated phenotypes earlier than usual, potentially leading to the early onset of neurodegenerative disorders and neurological decline (Fig. 4). While tracking adolescent RmTBI into adulthood has scarcely been researched, we do know that severe TBI in adolescence results in continuous verbal IQ decline and impairments in attention and working memory well into early adulthood [213]. Therefore, although adolescents are underrepresented in current TBI research, the literature to date suggests that

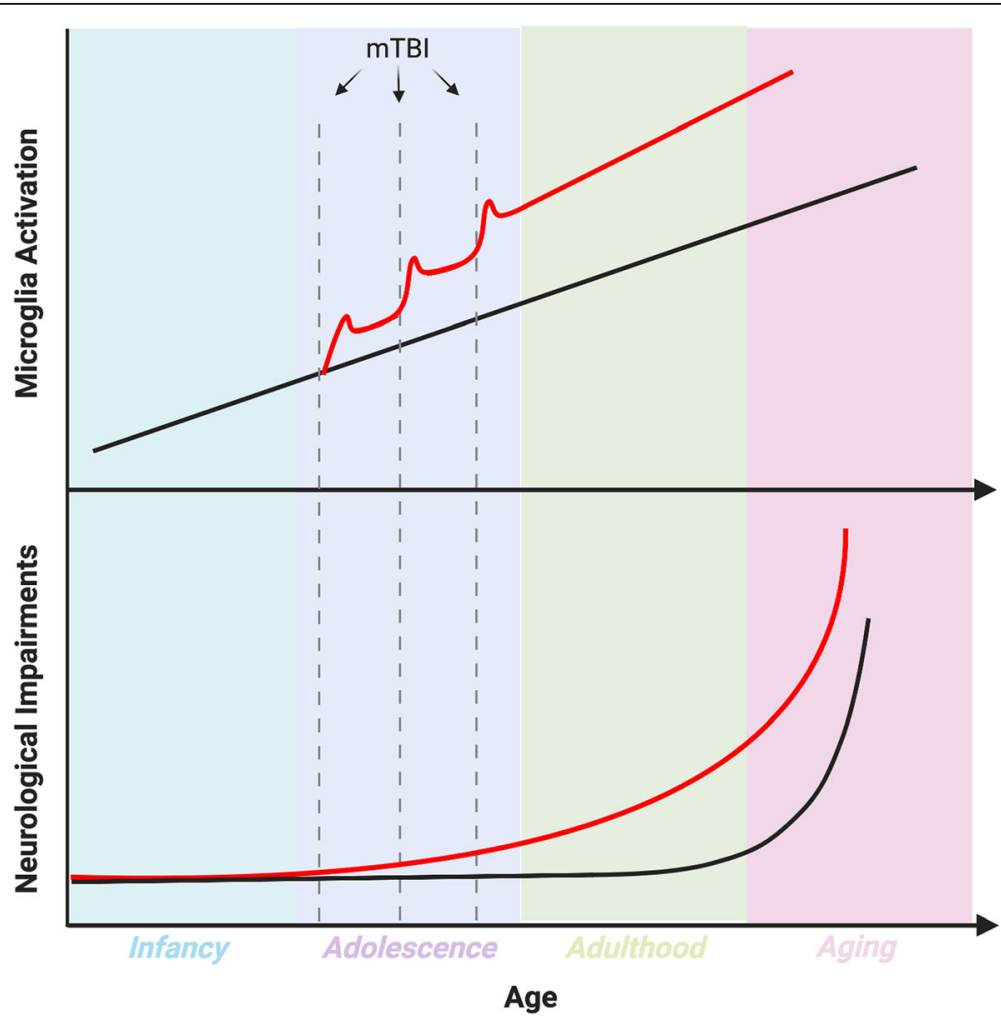

Fig. 4 Trends in microglia activation and neurological impairments following adolescent RmTBI. Throughout life, microglia are known to become increasingly activated. In addition, neurological impairments increase throughout adulthood and ageing. RmTBls sustained in adolescence may cause earlier chronic or primed microglia activation that may persist into adulthood and through aging. Increased microglia activation during the adolescent developmental period may therefore influence the acquisition or onset of neurological impairments throughout life. Disruption to neurological functioning may induce negative consequences through adulthood into aging 
receiving RmTBIs during adolescence may have far reaching consequences that require greater attention.

Research into mTBI and specifically RmTBI has seen a surge in recent years. However, the adolescent population has not been adequately studied and there is a specific void in the literature regarding the neuroinflammatory profile in this age group. Moreover, in the research that exists there is considerable variability and heterogeneity between studies. The main issues plaguing the mTBI research field are the lack of transparency and consistency in (1) model, (2) severity, (3) sex, (4) age and species, (5) time points for analysis, (6) number of injuries administered, and (7) inter-injury interval. For example, the inclusion of both males and females in basic and clinical research is of particular importance. Beginning in utero, and continuing throughout life, microglia development and transcriptional profiles differ between males and females. These differences in microglia phenotypes may manifest following injury and combine with sex-specific epigenetic changes, behavioral symptomologies, and microscopic structural changes to produce divergent pathological profiles. These differences are indicative of a non-uniform injury responses which have the potential to also impact therapeutic interventions and recovery. Given that the inflammatory profile differs based on each of the issues mentioned above and there is significant heterogeneity in the environmental factors surrounding injuries, it is currently difficult to draw specific conclusions regarding the role of microglia in adolescent and adult TBI pathophysiology. Notwithstanding, we have demonstrated that examination of the homeostatic and neurodevelopmental functions of microglia and immunological function during injury in adult states may provide novel insight into pathological consequences of activating these cells during adolescence. Sustaining injuries during this period has significant potential to alter developmental trajectories by augmenting microglial-dependent synaptic pruning, white matter tract development, and priming these cells to more activated phenotypes that could exacerbate neurological decline. The future however is bright. New technologies such as translocator protein (TPSO) autoradiography and positron emission technology (PET) have been developed to image microglia activation in vivo, in both humans [214-216] and rodents [217, 218]. These novel techniques open avenues to image microglia in living adolescents, which will be paramount to understanding this important aspect of neuroinflammation during such a critical period of brain development.

\section{Acknowledgements}

The authors would like to thank the Hotchkiss Brain Institute, the Alberta Children's Hospital Research Institute, Canadian Institute of Health Research, and Natural Sciences and Engineering Research Council for their financial contributions. The authors have no competing financial interests with respect to the work described here. All figures were generated with BioRender

\section{Authors' contributions}

$\mathrm{EE}$, RM, and AWL defined the research of interest and were involved in topic selection. EE carried out the literature review and wrote the first draft of the manuscript. AK, RM, and AWL reviewed the manuscript and made contributions for improvement. EE, AK, RM, and AWL aided in figure design and AK prepared the finished products. All authors read and approved the final manuscript.

\section{Funding}

This review article was funded specifically by NSERC grant RGPIN-2019-06274 (A.W. L.) and CIHR grant PTJ-153051 (R. M.).

\section{Availability of data and materials \\ Not applicable.}

Ethics approval and consent to participate

Not applicable.

Consent for publication

Not applicable.

\section{Competing interests}

The authors declare no competing interest.

\section{Author details}

${ }^{1}$ Department of Psychology, University of Calgary, 2500 University Drive NW, Calgary, AB T2N1N4, Canada. ${ }^{2}$ Hotchkiss Brain Institute, University of Calgary, 3330 Hospital Drive NW, Calgary, AB T2N4N1, Canada. ${ }^{3}$ Alberta Children's Hospital Research Institute, University of Calgary, 3330 Hospital Drive, NW, Calgary, AB T2N4N1, Canada. ${ }^{4}$ Department of Neuroscience, Monash

University, 6th Floor, The Alfred Centre, 99 Commercial Road, Melbourne, VIC 3004, Australia. ${ }^{5}$ Department of Cell Biology and Anatomy, University of Calgary, 3330 Hospital Drive NW, Calgary, AB T2N4N1, Canada.

Received: 15 June 2020 Accepted: 8 October 2020

Published online: 29 October 2020

\section{References}

1. Caro D. Towards sustainable traumatic brain injury care systems: Healthcare leadership imperatives in Canada. In Healthcare management forum. Los Angeles: SAGE Publications; 2011. p. 25-30.

2. Dewan MC, Mummareddy N, Wellons III JC, Bonfield CM: Epidemiology of global pediatric traumatic brain injury: qualitative review. World neurosurgery 2016, 91:497-509. e491.

3. Bruns $\mathrm{J} \mathrm{Jr}$, Hauser WA. The epidemiology of traumatic brain injury: a review. Epilepsia. 2003:44:2-10.

4. Emery C, Palacios-Derflingher L, Black AM, Eliason P, Krolikowski M, Spencer N, Kozak S, Schneider KJ, Babul S, Mrazik M: Does disallowing body checking in non-elite 13-to 14-year-old ice hockey leagues reduce rates of injury and concussion? A cohort study in two Canadian provinces. British Journal of Sports Medicine 2019:bjsports-2019-101092.

5. Guskiewicz KM, McCrea M, Marshall SW, Cantu RC, Randolph C, Barr W, Onate JA, Kelly JP. Cumulative effects associated with recurrent concussion in collegiate football players: the NCAA Concussion Study. Jama. 2003;290: 2549-55.

6. Kerr ZY, Chandran A, Nedimyer AK, Arakkal A, Pierpoint LA, Zuckerman SL. Concussion incidence and trends in 20 high school sports. Pediatrics. 2019;144.

7. Muir KW, Tyrrell P, Sattar N, Warburton E. Inflammation and ischaemic stroke. Current opinion in neurology. 2007;20:334-42.

8. Blasko I, Stampfer-Kountchev M, Robatscher P, Veerhuis R, Eikelenboom P, Grubeck-Loebenstein B. How chronic inflammation can affect the brain and support the development of Alzheimer's disease in old age: the role of microglia and astrocytes. Aging cell. 2004;3:169-76.

9. Bitsch A, Schuchardt J, Bunkowski S, Kuhlmann T, Brück W. Acute axonal injury in multiple sclerosis: correlation with demyelination and inflammation. Brain. 2000;123:1174-83.

10. Douaud G, Smith S, Jenkinson M, Behrens T, Johansen-Berg H, Vickers J, James S, Voets N, Watkins K, Matthews PM. Anatomically related grey and white matter abnormalities in adolescent-onset schizophrenia. Brain. 2007; 130:2375-86. 
11. Kaplow JB, Curran PJ, Dodge KA. Child, parent, and peer predictors of earlyonset substance use: A multisite longitudinal study. Journal of abnormal child psychology. 2002;30:199-216.

12. Michael K, Ben-Zur H. Risk-taking among adolescents: Associations with social and affective factors. Journal of adolescence. 2007;30:17-31.

13. Majdan M, Mauritz W, Brazinova A, Rusnak M, Leitgeb J, Janciak I, Wilbacher I. Severity and outcome of traumatic brain injuries (TBI) with different causes of injury. Brain injury. 2011;25:797-805.

14. Goodrich GL, Flyg HM, Kirby JE, Chang C-Y, Martinsen GL. Mechanisms of $\mathrm{TBI}$ and visual consequences in military and veteran populations. Optometry and Vision Science. 2013;90:105-12.

15. Meaney DF, Smith DH. Biomechanics of concussion. Clinics in sports medicine. 2011:30:19-31.

16. Len T, Neary J. Cerebrovascular pathophysiology following mild traumatic brain injury. Clinical physiology and functional imaging. 2011;31:85-93.

17. Shah-Basak PP, Urbain C, Wong S, Da Costa L, Pang EW, Dunkley BT, Taylor MJ. Concussion alters the functional brain processes of visual attention and working memory. Journal of neurotrauma. 2018;35:267-77.

18. Martin AK, Petersen AJ, Sesma HW, Koolmo MB, Ingram KM, Slifko KB, Nguyen VN, Doss RC, Linabery AM: Concussion symptomology and recovery in children and adolescents with pre-existing anxiety. Journal of Neurology, Neurosurgery \& Psychiatry 2020.

19. Chandran A, Elmi A, Young H, DiPietro L. Determinants of concussion diagnosis, symptomology, and resolution time in US high school soccer players. Research in sports medicine. 2020;28:42-54.

20. Späni CB, Braun DJ, Van Eldik L. Sex-related responses after traumatic brain injury: Considerations for preclinical modeling. Frontiers in neuroendocrinology. 2018;50:52-66.

21. Covassin T, Elbin R, Bleecker A, Lipchik A, Kontos AP. Are there differences in neurocognitive function and symptoms between male and female soccer players after concussions? The American journal of sports medicine. 2013;41: 2890-5

22. Babcock L, Byczkowski T, Wade SL, Ho M, Mookerjee S, Bazarian JJ. Predicting postconcussion syndrome after mild traumatic brain injury in children and adolescents who present to the emergency department. JAMA pediatrics. 2013;167:156-61.

23. McCrea M, Broglio S, McAllister T, Zhou W, Zhao S, Katz B, Kudela M, Harezlak J, Nelson L, Meier T. Return to play and risk of repeat concussion in collegiate football players: comparative analysis from the NCAA Concussion Study (1999-2001) and CARE Consortium (2014-2017). British journal of sports medicine. 2020;54:102-9.

24. Kerr ZY, Zuckerman SL, Wasserman EB, Covassin T, Djoko A, Dompier TP. Concussion symptoms and return to play time in youth, high school, and college American football athletes. JAMA pediatrics. 2016;170:647-53.

25. Sabatino MJ, Zynda AJ, Miller S: Same-day return to play after pediatric athletes sustain concussions. Am Acad Pediatrics; 2018.

26. Smith DH, Johnson VE, Stewart W. Chronic neuropathologies of single and repetitive TBl: substrates of dementia? Nature Reviews Neurology. 2013;9:211.

27. Corps KN, Roth TL, McGavern DB. Inflammation and neuroprotection in traumatic brain injury. JAMA neurology. 2015;72:355-62.

28. Theeler B, Lucas S, Riechers RG, Ruff RL. Post-traumatic headaches in civilians and military personnel: A comparative, clinical review. Headache: The Journal of Head and Face Pain. 2013;53:881-900.

29. Curry AE, Arbogast KB, Metzger KB, Kessler RS, Breiding MJ, Haarbauer-Krupa J, DePadilla L, Greenspan A, Master CL: Risk of repeat concussion among patients diagnosed at a pediatric care network. The Journal of pediatrics 2019.

30. Preiss-Farzanegan SJ, Chapman B, Wong TM, Wu J, Bazarian JJ. The relationship between gender and postconcussion symptoms after sportrelated mild traumatic brain injury. PM\&R. 2009;1:245-53.

31. Kerr ZY, Register-Mihalik JK, Kroshus E, Baugh CM, Marshall SW. Motivations associated with nondisclosure of self-reported concussions in former collegiate athletes. The American journal of sports medicine. 2016:44:220-5.

32. Sun M, McDonald S, Brady R, Collins-Praino L, Yamakawa G, Monif M, O'Brien T, Coud G, Sobey C, Mychasiuk R, Loane D, Shultz S. The need to incorporate aged animals into the preclinical modeling of neurological conditions. Neuroscience and Biobehavioural Reviews. 2020.

33. Whitford TJ, Rennie CJ, Grieve SM, Clark CR, Gordon E, Williams LM. Brain maturation in adolescence: concurrent changes in neuroanatomy and neurophysiology. Human brain mapping. 2007;28:228-37.

34. Longhi L, Saatman KE, Fujimoto S, Raghupathi R, Meaney DF, Davis J, McMillan A, Conte V, Laurer HL, Stein S. Temporal window of vulnerability to repetitive experimental concussive brain injury. Neurosurgery. 2005;56: 364-74.

35. Petraglia AL, Plog BA, Dayawansa S, Chen M, Dashnaw ML, Czerniecka K, Walker CT, Viterise T, Hyrien O, Iliff JJ. The spectrum of neurobehavioral sequelae after repetitive mild traumatic brain injury: a novel mouse model of chronic traumatic encephalopathy. Journal of neurotrauma. 2014;31:1211-24.

36. Mannix R, Meehan WP, Mandeville J, Grant PE, Gray T, Berglass J, Zhang J, Bryant J, Rezaie S, Chung JY. Clinical correlates in an experimental model of repetitive mild brain injury. Annals of neurology. 2013;74:65-75.

37. Mouzon BC, Bachmeier C, Ferro A, Ojo JO, Crynen G, Acker CM, Davies P, Mullan M, Stewart W, Crawford F. Chronic neuropathological and neurobehavioral changes in a repetitive mild traumatic brain injury model. Annals of neurology. 2014;75:241-54.

38. Yamakawa GR, Lengkeek C, Salberg S, Spanswick SC, Mychasiuk R. Behavioral and pathophysiological outcomes associated with caffeine consumption and repetitive mild traumatic brain injury (RmTBI) in adolescent rats. PLoS one. 2017;12:e0187218.

39. Wright D, O'Brien T, Shultz SR, Mychasiuk R. Sex matters: Repetitive mild traumatic brain injury in adolescent rats. Annals of Clinical and Translational Neurology. 2017:4:640-54.

40. Mannix R, Berkner J, Mei Z, Alcon S, Hashim J, Robinson S, Jantzie L, Meehan WP III, Qiu J. Adolescent mice demonstrate a distinct pattern of injury after repetitive mild traumatic brain injury. Journal of neurotrauma. 2017;34:495-504.

41. Salberg S, Christensen J, Yamakawa GR, Lengkeek C, Malik H, Tabor J, Hazari A, Mychasiuk R. A bump on the head or late to bed: behavioral and pathophysiological effects of sleep deprivation after repetitive mild traumatic brain injury in adolescent rats. Journal of neurotrauma. 2018;35: 1895-905.

42. Salberg S, Weerwardhena H, Collins R, Reimer RA, Mychasiuk R. The behavioural and pathophysiological effects of the ketogenic diet on mild traumatic brain injury in adolescent rats. Behavioural brain research. 2019; 376:112225

43. Christensen J, Yamakawa GR, Salberg S, Wang M, Kolb B, Mychasiuk R. Caffeine consumption during development alters spine density and recovery from repetitive mild traumatic brain injury in young adult rats. Synapse. 2019

44. Yamakawa GR, Weerawardhena H, Eyolfson E, Griep Y, Antle MC, Mychasiuk $R$. Investigating the role of the hypothalamus in outcomes to repetitive mild traumatic brain injury: neonatal monosodium glutamate does not exacerbate deficits. Neuroscience. 2019.

45. Christensen J, Eyolfson E, Salberg S, Bhatt D, Weerawardhena H, Tabor J, Mychasiuk R. When two wrongs make a right: the effect of acute and chronic binge drinking on traumatic brain injury outcomes in young adult female rats. Journal of neurotrauma. 2019.

46. Liu X, Qiu J, Alcon S, Hashim J, Meehan WP III, Mannix R. Environmental enrichment mitigates deficits after repetitive mild traumatic brain injury. Journal of neurotrauma. 2017;34:2445-55.

47. Tabor J, Collins R, Debert CT, Shultz SR, Mychasiuk R. Neuroendocrine whiplash: slamming the breaks on anabolic-androgenic steroids following repetitive mild traumatic brain injury in rats may worsen outcomes. Frontiers in neurology. 2019;10.

48. Smith DH, Meaney DF, Shull WH. Diffuse axonal injury in head trauma. The Journal of head trauma rehabilitation. 2003;18:307-16.

49. Johnson VE, Stewart W, Smith DH. Axonal pathology in traumatic brain injury. Experimental neurology. 2013;246:35-43.

50. Browne KD, Chen X-H, Meaney DF, Smith DH. Mild traumatic brain injury and diffuse axonal injury in swine. Journal of neurotrauma. 2011;28:1747-55.

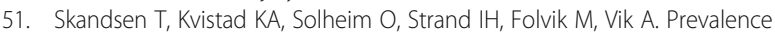
and impact of diffuse axonal injury in patients with moderate and severe head injury: a cohort study of early magnetic resonance imaging findings and 1-year outcome. Journal of neurosurgery. 2010;113:556-63.

52. Wallesch C-W, Curio N, Kutz S, Jost S, Bartels C, Synowitz H. Outcome after mild-to-moderate blunt head injury: effects of focal lesions and diffuse axonal injury. Brain injury. 2001;15:401-12.

53. Smith DH, Wolf JA, Lusardi TA, Lee VM-Y, Meaney DF. High tolerance and delayed elastic response of cultured axons to dynamic stretch injury. Journal of Neuroscience. 1999;19:4263-9.

54. Wolf JA, Stys PK, Lusardi T, Meaney D, Smith DH. Traumatic axonal injury induces calcium influx modulated by tetrodotoxin-sensitive sodium channels. Journal of Neuroscience. 2001;21:1923-30. 
55. Maxwell W, Graham D. Loss of axonal microtubules and neurofilaments after stretch-injury to guinea pig optic nerve fibers. Journal of neurotrauma. 1997;14:603-14.

56. Tang-Schomer MD, Johnson VE, Baas PW, Stewart W, Smith DH. Partial interruption of axonal transport due to microtubule breakage accounts for the formation of periodic varicosities after traumatic axonal injury. Experimental neurology. 2012;233:364-72.

57. Baker AJ, Phan N, Moulton RJ, Fehlings MG, Yucel Y, Zhao M, Liu E, Tian G. Attenuation of the electrophysiological function of the corpus callosum after fluid percussion injury in the rat. Journal of neurotrauma. 2002;19:587-99.

58. Reeves TM, Phillips LL, Povlishock JT. Myelinated and unmyelinated axons of the corpus callosum differ in vulnerability and functional recovery following traumatic brain injury. Experimental neurology. 2005;196:126-37.

59. Ziogas NK, Koliatsos VE. Primary traumatic axonopathy in mice subjected to impact acceleration: a reappraisal of pathology and mechanisms with highresolution anatomical methods. Journal of neuroscience. 2018;38:4031-47.

60. Xu L, Nguyen JV, Lehar M, Menon A, Rha E, Arena J, Ryu J, Marsh-Armstrong $\mathrm{N}$, Marmarou CR, Koliatsos VE. Repetitive mild traumatic brain injury with impact acceleration in the mouse: multifocal axonopathy, neuroinflammation, and neurodegeneration in the visual system. Experimental neurology. 2016;275:436-49.

61. Giza CC, Hovda DA. The neurometabolic cascade of concussion. Journal of athletic training. 2001;36:228.

62. Barkhoudarian G, Hovda DA, Giza CC. The molecular pathophysiology of concussive brain injury-an update. Physical Medicine and Rehabilitation Clinics. 2016;27:373-93.

63. Ren Z, lliff JJ, Yang L, Yang J, Chen X, Chen MJ, Giese RN, Wang B, Shi X, Nedergaard M. 'Hit \& Run'model of closed-skull traumatic brain injury (TBI) reveals complex patterns of post-traumatic AQP4 dysregulation. Journal of Cerebral Blood Flow \& Metabolism. 2013:33:834-45.

64. Murugan M, Santhakumar V, Kannurpatti SS. Facilitating mitochondrial calcium uptake improves activation-induced cerebral blood flow and behavior after mTBI. Frontiers in systems neuroscience. 2016;10:19.

65. Fischer TD, Hylin MJ, Zhao J, Moore AN, Waxham MN, Dash PK. Altered mitochondrial dynamics and TBI pathophysiology. Frontiers in systems neuroscience. 2016;10:29.

66. Xiong Y, Mahmood A, Chopp M. Animal models of traumatic brain injury. Nature Reviews Neuroscience. 2013;14:128.

67. Mandera M, Larysz D, Wojtacha M. Changes in cerebral hemodynamics assessed by transcranial Doppler ultrasonography in children after head injury. Child's nervous system. 2002;18:124-8.

68. Wang H, Lynch JR, Song P, Yang H-J, Yates RB, Mace B, Warner DS, Guyton JR, Laskowitz DT. Simvastatin and atorvastatin improve behavioral outcome, reduce hippocampal degeneration, and improve cerebral blood flow after experimental traumatic brain injury. Experimental neurology. 2007;206:59-69.

69. Bergsneider M, Hovda DA, Shalmon E, Kelly DF, Vespa PM, Martin NA, Phelps ME, McArthur DL, Caron MJ, Kraus JF, Becker DP. Cerebral hyperglycolysis following severe traumatic brain injury in humans: a positron emission tomography study. J Neurosurg. 1997:86:241-51.

70. Yoshino A, Hovda DA, Kawamata T, Katayama Y, Becker DP. Dynamic changes in local cerebral glucose utilization following cerebral conclusion in rats: evidence of a hyper- and subsequent hypometabolic state. Brain Res. 1991:561:106-19.

71. Bergsneider M, Hovda DA, Lee SM, Kelly DF, McArthur DL, Vespa PM, Lee $J H$, Huang SC, Martin NA, Phelps ME, Becker DP. Dissociation of cerebral glucose metabolism and level of consciousness during the period of metabolic depression following human traumatic brain injury. $J$ Neurotrauma. 2000;17:389-401.

72. Bergsneider M, Hovda DA, McArthur DL, Etchepare M, Huang SC, Sehati N, Satz P, Phelps ME, Becker DP. Metabolic recovery following human traumatic brain injury based on FDG-PET: time course and relationship to neurological disability. J Head Trauma Rehabil. 2001;16:135-48.

73. Yamakami I, Mclntosh TK. Alterations in regional cerebral blood flow following brain injury in the rat. Journal of Cerebral Blood Flow \& Metabolism. 1991;11:655-60.

74. Clark AL, Weigand AJ, Bangen KJ, Merritt VC, Bondi MW, Delano-Wood L: Repetitive $\mathrm{mTBI}$ is associated with age-related reductions in cerebral blood flow but not cortical thickness. J Cereb Blood Flow Metab 2020: 271678X19897443.

75. Ojo JO, Mouzon B, Algamal M, Leary P, Lynch C, Abdullah L, Evans J, Mullan M, Bachmeier C, Stewart W, Crawford F. Chronic repetitive mild traumatic brain injury results in reduced cerebral blood flow, axonal injury, gliosis, and increased T-Tau and Tau oligomers. J Neuropathol Exp Neurol. 2016;75:636-55.

76. Peskind ER, Petrie EC, Cross DJ, Pagulayan K, McCraw K, Hoff D, Hart K, Yu CE, Raskind MA, Cook DG, Minoshima S. Cerebrocerebellar hypometabolism associated with repetitive blast exposure mild traumatic brain injury in 12 Iraq war Veterans with persistent post-concussive symptoms. Neuroimage. 2011;54(Suppl 1):S76-82

77. Sankar SB, Pybus AF, Liew A, Sanders B, Shah KJ, Wood LB, Buckley EM. Low cerebral blood flow is a non-invasive biomarker of neuroinflammation after repetitive mild traumatic brain injury. Neurobiology of disease. 2019;124:544-54.

78. LaPlaca MC, Lessing MC, Prado GR, Zhou R, Tate CC, Geddes-Klein D, Meaney DF, Zhang L. Mechanoporation is a potential indicator of tissue strain and subsequent degeneration following experimental traumatic brain injury. Clinical Biomechanics. 2019;64:2-13.

79. Farkas O, Lifshitz J, Povlishock JT. Mechanoporation induced by diffuse traumatic brain injury: an irreversible or reversible response to injury? Journal of Neuroscience. 2006;26:3130-40.

80. DiSabato DJ, Quan N, Godbout JP. Neuroinflammation: the devil is in the details. Journal of neurochemistry. 2016;139:136-53.

81. Hughes AN, Appel B. Microglia phagocytose myelin sheaths to modify developmental myelination. Nature Neuroscience. 2020:1-12.

82. Habib P, Slowik A, Zendedel A, Johann S, Dang J, Beyer C. Regulation of hypoxia-induced inflammatory responses and M1-M2 phenotype switch of primary rat microglia by sex steroids. Journal of Molecular Neuroscience. 2014:52:277-85.

83. Aryanpour R, Pasbakhsh P, Zibara K, Namjoo Z, Boroujeni FB, Shahbeigi S, Kashani IR, Beyer C, Zendehdel A. Progesterone therapy induces an M1 to M2 switch in microglia phenotype and suppresses NLRP3 inflammasome in a cuprizone-induced demyelination mouse model. International immunopharmacology. 2017;51:131-9.

84. Yao X, Liu S, Ding W, Yue P, Jiang Q, Zhao M, Hu F, Zhang H. TLR4 signal ablation attenuated neurological deficits by regulating microglial M1/M2 phenotype after traumatic brain injury in mice. Journal of Neuroimmunology. 2017:310:38-45.

85. McPherson C, Merrick B, Harry G. In vivo molecular markers for proinflammatory cytokine M1 stage and resident microglia in trimethyltininduced hippocampal injury. Neurotoxicity research. 2014;25:45-56.

86. Norden DM, Trojanowski PJ, Villanueva E, Navarro E, Godbout JP. Sequential activation of microglia and astrocyte cytokine expression precedes increased iba-1 or GFAP immunoreactivity following systemic immune challenge. Glia. 2016;64:300-16.

87. Schumann J, Alexandrovich GA, Biegon A, Yaka R. Inhibition of NR2B phosphorylation restores alterations in NMDA receptor expression and improves functional recovery following traumatic brain injury in mice. Journal of neurotrauma. 2008:25:945-57.

88. Chen T, Dai S-H, Jiang Z-Q, Luo P, Jiang X-F, Fei Z, Gui S-B, Qi Y-L. The AMPAR antagonist perampanel attenuates traumatic brain injury through anti-oxidative and anti-inflammatory activity. Cellular and molecular neurobiology. 2017:37:43-52.

89. Laffer B, Bauer D, Wasmuth S, Busch M, Jalilvand TV, Thanos S, Meyer Zu Horste G, Loser K, Langmann T, Heiligenhaus A. Loss of IL-10 promotes differentiation of microglia to a M1 phenotype. Frontiers in cellular neuroscience. 2019:13:430.

90. Savage CD, Lopez-Castejon G, Denes A, Brough D. NLRP3-inflammasome activating DAMPs stimulate an inflammatory response in glia in the absence of priming which contributes to brain inflammation after injury. Frontiers in immunology. 2012;3:288

91. Manson J, Thiemermann C, Brohi K. Trauma alarmins as activators of damage-induced inflammation. British journal of surgery. 2012;99:12-20.

92. Weissberg I, Veksler R, Kamintsky L, Saar-Ashkenazy R, Milikovsky DZ, Shelef I, Friedman A. Imaging blood-brain barrier dysfunction in football players. JAMA neurology. 2014;71:1453-5.

93. Afonso PV, Ozden S, Cumont M-C, Seilhean D, Cartier L, Rezaie P, Mason S, Lambert S, Huerre M, Gessain A. Alteration of blood-brain barrier integrity by retroviral infection. PLOS Pathog. 2008:4:e1000205.

94. Chodobski A, Zink BJ, Szmydynger-Chodobska J. Blood-brain barrier pathophysiology in traumatic brain injury. Translational stroke research. 2011; 2:492-516.

95. Başkaya MK, Rao AM, Doğan A, Donaldson D, Dempsey RJ. The biphasic opening of the blood-brain barrier in the cortex and hippocampus after traumatic brain injury in rats. Neuroscience letters. 1997;226:33-6. 
96. Shetty AK, Mishra V, Kodali M, Hattiangady B. Blood brain barrier dysfunction and delayed neurological deficits in mild traumatic brain injury induced by blast shock waves. Frontiers in cellular neuroscience. 2014;8:232.

97. Yang SH, Gustafson J, Gangidine M, Stepien D, Schuster R, Pritts TA, Goodman MD, Remick DG, Lentsch AB: A murine model of mild traumatic brain injury exhibiting cognitive and motor deficits. journal of surgical research 2013, 184:981-988.

98. Kane MJ, Angoa-Pérez M, Briggs DI, Viano DC, Kreipke CW, Kuhn DM. A mouse model of human repetitive mild traumatic brain injury. Journal of neuroscience methods. 2012;203:41-9.

99. Zohar O, Schreiber S, Getslev V, Schwartz J, Mullins P, Pick C. Closed-head minimal traumatic brain injury produces long-term cognitive deficits in mice. Neuroscience. 2003;118:949-55.

100. O'Connor C, Cernak I, Vink R. The temporal profile of edema formation differs between male and female rats following diffuse traumatic brain injury. In Brain Edema XIII. Springer. 2006:121-4.

101. Bye N, Habgood MD, Callaway JK, Malakooti N, Potter A, Kossmann T, Morganti-Kossmann MC. Transient neuroprotection by minocycline following traumatic brain injury is associated with attenuated microglial activation but no changes in cell apoptosis or neutrophil infiltration. Experimental neurology. 2007;204:220-33.

102. Stahel PF, Shohami E, Younis FM, Kariya K, Otto VI, Lenzlinger PM, Grosjean MB, Eugster H-P, Trentz O, Kossmann T. Experimental closed head injury: analysis of neurological outcome, blood-brain barrier dysfunction, intracranial neutrophil infiltration, and neuronal cell death in mice deficient in genes for pro-inflammatory cytokines. Journal of Cerebral Blood Flow \& Metabolism. 2000;20:369-80.

103. Soares HD, Hicks RR, Smith D, McIntosh TK. Inflammatory leukocytic recruitment and diffuse neuronal degeneration are separate pathological processes resulting from traumatic brain injury. Journal of Neuroscience. 1995; 15:8223-33.

104. Hsieh CL, Kim CC, Ryba BE, Niemi EC, Bando JK, Locksley RM, Liu J, Nakamura MC, Seaman WE. Traumatic brain injury induces macrophage subsets in the brain. European journal of immunology. 2013:43:2010-22.

105. Hsieh CL, Niemi EC, Wang SH, Lee CC, Bingham D, Zhang J, Cozen ML, Charo I, Huang EJ, Liu J. CCR2 deficiency impairs macrophage infiltration and improves cognitive function after traumatic brain injury. Journal of neurotrauma. 2014;31:1677-88.

106. Hausmann R, Kaiser A, Lang C, Bohnert M, Betz P. A quantitative immunohistochemical study on the time-dependent course of acute inflammatory cellular response to human brain injury. International journal of legal medicine. 1999;112:227-32.

107. Gyoneva S, Ransohoff RM. Inflammatory reaction after traumatic brain injury: therapeutic potential of targeting cell-cell communication by chemokines. Trends in pharmacological sciences. 2015;36:471-80.

108. Simon DW, McGeachy MJ, Bayır H, Clark RS, Loane DJ, Kochanek PM. The far-reaching scope of neuroinflammation after traumatic brain injury. Nature Reviews Neurology. 2017;13:171.

109. Kopec AM, Smith CJ, Ayre NR, Sweat SC, Bilbo SD. Microglial dopamine receptor elimination defines sex-specific nucleus accumbens development and social behavior in adolescent rats. Nature communications. 2018;9:3769.

110. Lenz KM, Nugent BM, Haliyur R, McCarthy MM. Microglia are essential to masculinization of brain and behavior. Journal of Neuroscience. 2013;33: 2761-72.

111. Nelson LH, Warden S, Lenz KM. Sex differences in microglial phagocytosis in the neonatal hippocampus. Brain, behavior, and immunity. 2017;64:11-22.

112. Kilb W. Development of the GABAergic system from birth to adolescence. The Neuroscientist. 2012;18:613-30

113. Larsen B, Luna B. Adolescence as a neurobiological critical period for the development of higher-order cognition. Neuroscience \& Biobehavioral Reviews. 2018;94:179-95.

114. Kolb B, Mychasiuk R, Muhammad A, Li Y, Frost DO, Gibb R. Experience and the developing prefrontal cortex. Proceedings of the National Academy of Sciences. 2012;109:17186-93.

115. Sisk CL, Foster DL. The neural basis of puberty and adolescence. Nature neuroscience. 2004:7:1040.

116. Merikangas KR. He J-p, Burstein M, Swanson SA, Avenevoli S, Cui L, Benjet C, Georgiades K, Swendsen J: Lifetime prevalence of mental disorders in US adolescents: results from the National Comorbidity Survey ReplicationAdolescent Supplement (NCS-A). Journal of the American Academy of Child \& Adolescent Psychiatry. 2010;49:980-9.
117. Blakemore SJ, Burnett S, Dahl RE. The role of puberty in the developing adolescent brain. Human brain mapping. 2010;31:926-33.

118. Spear LP. Neurobehavioral changes in adolescence. Current directions in psychological science. 2000;9:111-4.

119. Zuo Y, Lin A, Chang P, Gan W-B. Development of long-term dendritic spine stability in diverse regions of cerebral cortex. Neuron. 2005;46:181-9.

120. Benes FM, Turtle M, Khan Y, Farol P. Myelination of a key relay zone in the hippocampal formation occurs in the human brain during childhood, adolescence, and adulthood. Archives of general psychiatry. 1994;51:477-84.

121. Lebel C, Deoni S. The development of brain white matter microstructure. Neuroimage. 2018;182:207-18.

122. Mills KL, Goddings A-L, Clasen LS, Giedd JN, Blakemore S-J. The developmental mismatch in structural brain maturation during adolescence. Developmental neuroscience. 2014;36:147-60.

123. Kolb B, Gorny G, Söderpalm AH, Robinson TE. Environmental complexity has different effects on the structure of neurons in the prefrontal cortex versus the parietal cortex or nucleus accumbens. Synapse. 2003;48:149-53.

124. Comeau WL, McDonald RJ, Kolb BE. Learning-induced alterations in prefrontal cortical dendritic morphology. Behavioural brain research. 2010; 214:91-101.

125. Peper JS, Brouwer RM, Schnack HG, van Baal GC, van Leeuwen M, van den Berg SM. Delemarre-Van de Waal HA, Boomsma DI, Kahn RS, Pol HEH: Sex steroids and brain structure in pubertal boys and girls. Psychoneuroendocrinology. 2009;34:332-42.

126. Asato M, Terwilliger R, Woo J, Luna B. White matter development in adolescence: a DTI study. Cerebral cortex. 2010;20:2122-31.

127. Seunarine KK, Clayden JD, Jentschke S, Munoz M, Cooper JM, Chadwick MJ, Banks T, Vargha-Khadem F, Clark CA. Sexual dimorphism in white matter developmental trajectories using tract-based spatial statistics. Brain connectivity. 2016:6:37-47.

128. Lebel C, Beaulieu C. Longitudinal development of human brain wiring continues from childhood into adulthood. Journal of Neuroscience. 2011;31: 10937-47.

129. Brouwer RM, Mandl RC, Schnack HG, van Soelen IL, van Baal GC, Peper JS, Kahn RS, Boomsma DI, Pol HH. White matter development in early puberty: a longitudinal volumetric and diffusion tensor imaging twin study. PloS one. 2012; 7:e32316.

130. Nayak D, Roth TL, McGavern DB. Microglia development and function. Annual review of immunology. 2014;32:367-402.

131. Ueno M, Fujita Y, Tanaka T, Nakamura Y, Kikuta J, Ishii M, Yamashita T. Layer $\checkmark$ cortical neurons require microglial support for survival during postnatal development. Nature neuroscience. 2013;16:543.

132. Tremblay M-Ė, Lowery RL, Majewska AK. Microglial interactions with synapses are modulated by visual experience. PLoS biology. 2010;8: e1000527.

133. Krabbe G, Minami SS, Etchegaray JI, Taneja P, Djukic B, Davalos D, Le D, Lo I, Zhan L, Reichert MC. Microglial NFkB-TNFa hyperactivation induces obsessive-compulsive behavior in mouse models of progranulin-deficient frontotemporal dementia. Proceedings of the National Academy of Sciences. 2017;114:5029-34

134. Hickman SE, Allison EK, El Khoury J. Microglial dysfunction and defective $\beta$ amyloid clearance pathways in aging Alzheimer's disease mice. Journal of Neuroscience. 2008;28:8354-60.

135. Ouchi Y, Yoshikawa E, Sekine Y, Futatsubashi M, Kanno T, Ogusu T, Torizuka T. Microglial activation and dopamine terminal loss in early Parkinson's disease. Annals of neurology. 2005;57:168-75.

136. Cherry JD, Tripodis Y, Alvarez VE, Huber B, Kiernan PT, Daneshvar DH, Mez J, Montenigro PH, Solomon TM, Alosco ML. Microglial neuroinflammation contributes to tau accumulation in chronic traumatic encephalopathy. Acta neuropathologica communications. 2016;4:1-9.

137. Marques CP, Hu S, Sheng W, Lokensgard JR. Microglial cells initiate vigorous yet non-protective immune responses during HSV-1 brain infection. Virus research. 2006;121:1-10.

138. Sierra A, Gottfried-Blackmore AC, McEwen BS, Bulloch K. Microglia derived from aging mice exhibit an altered inflammatory profile. Glia. 2007;55:412-24.

139. Xie Z, Morgan TE, Rozovsky I, Finch CE. Aging and glial responses to lipopolysaccharide in vitro: greater induction of IL-1 and IL-6, but smaller induction of neurotoxicity. Experimental neurology. 2003;182:135-41.

140. Tay TL, Savage JC, Hui CW, Bisht K, Tremblay MË. Microglia across the lifespan: from origin to function in brain development, plasticity and cognition. The Journal of physiology. 2017;595:1929-45. 
141. Verney C, Monier A, Fallet-Bianco C, Gressens P. Early microglial colonization of the human forebrain and possible involvement in periventricular whitematter injury of preterm infants. Journal of anatomy. 2010;217:436-48.

142. Ginhoux F, Greter M, Leboeuf M, Nandi S, See P, Gokhan S, Mehler MF, Conway SJ, Ng LG, Stanley ER. Fate mapping analysis reveals that adult microglia derive from primitive macrophages. Science. 2010;330:841-5.

143. Dalmau I, Vela JM, González B, Finsen B, Castellano B. Dynamics of microglia in the developing rat brain. Journal of comparative neurology. 2003;458:144-57.

144. Monier A, Evrard P, Gressens P, Verney C. Distribution and differentiation of microglia in the human encephalon during the first two trimesters of gestation. Journal of Comparative Neurology. 2006;499:565-82.

145. Monier A, Adle-Biassette H, Delezoide A-L, Evrard P, Gressens P, Verney C. Entry and distribution of microglial cells in human embryonic and fetal cerebral cortex. Journal of neuropathology and experimental neurology. 2007; 66:372-82.

146. Parakalan R, Jiang B, Nimmi B, Janani M, Jayapal M, Lu J, Tay SS, Ling E-A, Dheen ST. Transcriptome analysis of amoeboid and ramified microglia isolated from the corpus callosum of rat brain. BMC neuroscience. 2012;13:64.

147. Takata K, Kozaki T, Lee CZW, Thion MS, Otsuka M, Lim S, Utami KH, Fidan K, Park DS, Malleret B: Induced-pluripotent-stem-cell-derived primitive macrophages provide a platform for modeling tissue-resident macrophage differentiation and function. Immunity 2017, 47:183-198. e186.

148. Zhou T, Zhang J, Zhang L, Yi S, Jiang X, Qiao Y, Zhang Y, Xiao C. Mouse astrocytes promote microglial ramification by releasing TGF- $\beta$ and forming glial fibers. Frontiers in Cellular Neuroscience. 2020;14:195.

149. Matyash M, Zabiegalov O, Wendt S, Matyash V, Kettenmann H. The adenosine generating enzymes CD39/CD73 control microglial processes ramification in the mouse brain. PLoS One. 2017;12:e0175012.

150. Schilling T, Nitsch R, Heinemann U, Haas D, Eder C. Astrocyte-released cytokines induce ramification and outward $\mathrm{K}+$ channel expression in microglia via distinct signalling pathways. European Journal of Neuroscience. 2001:14:463-73.

151. Squarzoni P, Oller G, Hoeffel G, Pont-Lezica L, Rostaing P, Low D, Bessis A, Ginhoux F, Garel S. Microglia modulate wiring of the embryonic forebrain. Cell reports. 2014:8:1271-9.

152. Cunningham CL, Martínez-Cerdeño V, Noctor SC. Microglia regulate the number of neural precursor cells in the developing cerebral cortex. Journal of Neuroscience. 2013;33:4216-33.

153. Ajami B, Bennett JL, Krieger C, Tetzlaff W, Rossi FM. Local self-renewal can sustain CNS microglia maintenance and function throughout adult life. Nature neuroscience. 2007;10:1538.

154. Grabert K, Michoel T, Karavolos MH, Clohisey S, Baillie JK, Stevens MP, Freeman TC, Summers KM, McColl BW. Microglial brain region- dependent diversity and selective regional sensitivities to aging. Nature neuroscience. 2016;19:504-16.

155. Schwarz JM, Sholar PW, Bilbo SD. Sex differences in microglial colonization of the developing rat brain. Journal of neurochemistry. 2012;120:948-63.

156. Sellgren C, Sheridan S, Gracias J, Xuan D, Fu T, Perlis R. Patient-specific models of microglia-mediated engulfment of synapses and neural progenitors. Molecular psychiatry. 2017;22:170-7.

157. Sierra A, Encinas JM, Deudero JJ, Chancey JH, Enikolopov G, OverstreetWadiche LS, Tsirka SE, Maletic-Savatic M. Microglia shape adult hippocampal neurogenesis through apoptosis-coupled phagocytosis. Cell stem cell. 2010; 7:483-95.

158. Pont-Lezica L, Beumer W, Colasse S, Drexhage H, Versnel M, Bessis A. Microglia shape corpus callosum axon tract fasciculation: functional impact of prenatal inflammation. European Journal of Neuroscience. 2014;39:1551-7.

159. Bilimoria PM, Stevens B. Microglia function during brain development: new insights from animal models. Brain research. 1617;2015:7-17.

160. Paolicelli RC, Bolasco G, Pagani F, Maggi L, Scianni M, Panzanelli P, Giustetto $M$, Ferreira TA, Guiducci E, Dumas L: Synaptic pruning by microglia is necessary for normal brain development. science 2011, 333:1456-1458.

161. Krukowski K, Chou A, Feng X, Tiret B, Paladini M-S, Riparip L-K, Chaumeil MM, Lemere C, Rosi S. Traumatic brain injury in aged mice induces chronic microglia activation, synapse loss, and complement-dependent memory deficits. International journal of molecular sciences. 2018;19:3753.

162. Kim H, Cho M, Shim W, Kim J, Jeon E, Kim D, Yoon S. Deficient autophagy in microglia impairs synaptic pruning and causes social behavioral defects. Molecular psychiatry. 2017;22:1576-84.

163. Sellgren CM, Gracias J, Watmuff B, Biag JD, Thanos JM, Whittredge PB, Fu T, Worringer K, Brown HE, Wang J. Increased synapse elimination by microglia in schizophrenia patient-derived models of synaptic pruning. Nature neuroscience. 2019;22:374-85.

164. Mallya AP, Wang H-D, Lee HNR, Deutch AY. Microglial pruning of synapses in the prefrontal cortex during adolescence. Cerebral Cortex. 2018;29:1634-43.

165. Tremblay M-È, Stevens B, Sierra A, Wake H, Bessis A, Nimmerjahn A. The role of microglia in the healthy brain. Journal of Neuroscience. 2011;31:16064-9.

166. Tuan L-H, Lee L-J. Microglia-mediated synaptic pruning is impaired in sleepdeprived adolescent mice. Neurobiology of Disease. 2019;130:104517.

167. Linker K, Elabd M, Tawadrous P, Cano M, Green K, Wood M, Leslie F. Microglial activation increases cocaine self-administration following adolescent nicotine exposure. Nature Communications. 2020;11:1-14.

168. Alexander JJ, Anderson AJ, Barnum SR, Stevens B, Tenner AJ. The complement cascade: Yin-Yang in neuroinflammation-neuro-protection and-degeneration. Journal of neurochemistry. 2008;107:1169-87.

169. Stevens B, Allen NJ, Vazquez LE, Howell GR, Christopherson KS, Nouri N, Micheva KD, Mehalow AK, Huberman AD, Stafford B. The classical complement cascade mediates CNS synapse elimination. Cell. 2007;131: 1164-78.

170. Zabel MK, Kirsch WM. From development to dysfunction: microglia and the complement cascade in CNS homeostasis. Ageing research reviews. 2013;12: 749-56.

171. Kim DD, Song WC. Membrane complement regulatory proteins. Clin Immunol. 2006:118:127-36.

172. Zipfel PF, Skerka C. Complement regulators and inhibitory proteins. Nat Rev Immunol. 2009:9:729-40.

173. Hong S, Beja-Glasser VF, Nfonoyim BM, Frouin A, Li S, Ramakrishnan S, Merry KM, Shi Q, Rosenthal A, Barres BA. Complement and microglia mediate early synapse loss in Alzheimer mouse models. Science. 2016;352:712-6.

174. Kopec AM, Smith CJ, Ayre NR, Sweat SC, Bilbo SD. Microglial dopamine receptor elimination defines sex-specific nucleus accumbens development and social behavior in adolescent rats. Nat Commun. 2018;9:3769.

175. Shultz SR, MacFabe DF, Foley KA, Taylor R, Cain DP. Sub-concussive brain injury in the Long-Evans rat induces acute neuroinflammation in the absence of behavioral impairments. Behavioural brain research. 2012;229:145-52

176. Winston CN, Noël A, Neustadtl A, Parsadanian M, Barton DJ, Chellappa D, Wilkins TE, Alikhani AD, Zapple DN, Villapol S. Dendritic spine loss and chronic white matter inflammation in a mouse model of highly repetitive head trauma. The American journal of pathology. 2016;186:552-67.

177. Petraglia AL, Plog BA, Dayawansa S, Dashnaw ML, Czerniecka K, Walker CT, Chen $\mathrm{M}$, Hyrien $\mathrm{O}$, lliff JJ, Deane R. The pathophysiology underlying repetitive mild traumatic brain injury in a novel mouse model of chronic traumatic encephalopathy. Surgical neurology international. 2014;5.

178. Shitaka Y, Tran HT, Bennett RE, Sanchez L, Levy MA, Dikranian K, Brody DL. Repetitive closed-skull traumatic brain injury in mice causes persistent multifocal axonal injury and microglial reactivity. Journal of Neuropathology \& Experimental Neurology. 2011;70:551-67.

179. Mouzon B, Chaytow H, Crynen G, Bachmeier C, Stewart J, Mullan M, Stewart W, Crawford F. Repetitive mild traumatic brain injury in a mouse model produces learning and memory deficits accompanied by histological changes. Journal of neurotrauma. 2012;29:2761-73.

180. Fenn AM, Gensel JC, Huang Y, Popovich PG, Lifshitz J, Godbout JP. Immune activation promotes depression 1 month after diffuse brain injury: a role for primed microglia. Biological psychiatry. 2014;76:575-84.

181. Turtzo LC, Lescher J, Janes L, Dean DD, Budde MD, Frank JA. Macrophagic and microglial responses after focal traumatic brain injury in the female rat. Journal of neuroinflammation. 2014;11:82.

182. Namjoshi DR, Cheng WH, Bashir A, Wilkinson A, Stukas S, Martens KM, Whyte T, Abebe ZA, Mclnnes KA, Cripton PA. Defining the biomechanical and biological threshold of murine mild traumatic brain injury using $\mathrm{CHIM}$ ERA (Closed Head Impact Model of Engineered Rotational Acceleration). Experimental neurology. 2017;292:80-91.

183. Shultz SR, Bao F, Omana V, Chiu C, Brown A, Cain DP. Repeated mild lateral fluid percussion brain injury in the rat causes cumulative long-term behavioral impairments, neuroinflammation, and cortical loss in an animal model of repeated concussion. Journal of neurotrauma. 2012;29:281-94.

184. Robinson S, Berglass JB, Denson JL, Berkner J, Anstine CV, Winer JL, Maxwell JR, Qiu J, Yang Y, Sillerud LO. Microstructural and microglial changes after repetitive mild traumatic brain injury in mice. Journal of neuroscience research. 2017;95:1025-35.

185. Mannix R, Berglass J, Berkner J, Moleus P, Qiu J, Andrews N, Gunner G, Berglass $\mathrm{L}$, Jantzie $\mathrm{LL}$, Robinson $\mathrm{S}$. Chronic gliosis and behavioral deficits in 
mice following repetitive mild traumatic brain injury. Journal of neurosurgery. 2014;121:1342-50.

186. Fidan E, Lewis J, Kline AE, Garman RH, Alexander H, Cheng JP, Bondi CO, Clark RS, Dezfulian C, Kochanek PM. Repetitive mild traumatic brain injury in the developing brain: effects on long-term functional outcome and neuropathology. Journal of neurotrauma. 2016;33:641-51.

187. Jacobowitz DM, Cole JT, McDaniel DP, Pollard HB, Watson WD. Microglia activation along the corticospinal tract following traumatic brain injury in the rat: a neuroanatomical study. Brain research. 2012;1465:80-9.

188. Muccigrosso MM, Ford J, Benner B, Moussa D, Burnsides C, Fenn AM, Popovich PG, Lifshitz J, Walker FR, Eiferman DS. Cognitive deficits develop 1 month after diffuse brain injury and are exaggerated by microgliaassociated reactivity to peripheral immune challenge. Brain, behavior, and immunity. 2016;54:95-109.

189. Loane DJ, Kumar A, Stoica BA, Cabatbat R, Faden Al. Progressive neurodegeneration after experimental brain trauma: association with chronic microglial activation. Journal of Neuropathology \& Experimental Neurology. 2014;73:14-29.

190. Aungst SL, Kabadi SV, Thompson SM, Stoica BA, Faden Al. Repeated mild traumatic brain injury causes chronic neuroinflammation, changes in hippocampal synaptic plasticity, and associated cognitive deficits. Journal of Cerebral Blood Flow \& Metabolism. 2014;34:1223-32.

191. Collins-Praino LE, Arulsamy A, Katharesan V, Corrigan F. The effect of an acute systemic inflammatory insult on the chronic effects of a single mild traumatic brain injury. Behavioural brain research. 2018;336:22-31.

192. Mouton PR, Long JM, Lei D-L, Howard V, Jucker M, Calhoun ME, Ingram DK. Age and gender effects on microglia and astrocyte numbers in brains of mice. Brain research. 2002;956:30-5.

193. Tremblay MË, Zettel ML, Ison JR, Allen PD, Majewska AK. Effects of aging and sensory loss on glial cells in mouse visual and auditory cortices. Glia. 2012;60:541-58

194. Sandhir R, Onyszchuk G, Berman NE. Exacerbated glial response in the aged mouse hippocampus following controlled cortical impact injury. Experimental neurology. 2008;213:372-80.

195. Kumar A, Stoica BA, Sabirzhanov B, Burns MP, Faden Al, Loane DJ. Traumatic brain injury in aged animals increases lesion size and chronically alters microglial/macrophage classical and alternative activation states. Neurobiology of aging. 2013;34:1397-411.

196. Johnson VE, Stewart JE, Begbie FD, Trojanowski JQ, Smith DH, Stewart W. Inflammation and white matter degeneration persist for years after a single traumatic brain injury. Brain. 2013;136:28-42.

197. Ramlackhansingh AF, Brooks DJ, Greenwood RJ, Bose SK, Turkheimer FE, Kinnunen KM, Gentleman S, Heckemann RA, Gunanayagam K, Gelosa G. Inflammation after trauma: microglial activation and traumatic brain injury. Annals of neurology. 2011;70:374-83.

198. Coughlin JM, Wang Y, Munro CA, Ma S, Yue C, Chen S, Airan R, Kim PK, Adams AV, Garcia C. Neuroinflammation and brain atrophy in former NFL players: an in vivo multimodal imaging pilot study. Neurobiology of disease. 2015;74:58-65.

199. Wu L, Chung JY, Saith S, Tozzi L, Buckley EM, Sanders B, Franceschini MA, Lule S, Izzy S, Lok J. Repetitive head injury in adolescent mice: A role for vascular inflammation. Journal of Cerebral Blood Flow \& Metabolism. 2019;39:2196-209.

200. Newell EA, Todd BP, Luo Z, Evans LP, Ferguson PJ, Bassuk AG. A mouse model for juvenile, lateral fluid percussion brain injury reveals sexdependent differences in neuroinflammation and functional recovery. Journal of Neurotrauma. 2020;37:635-46.

201. Hehar H, Yeates K, Kolb B, Esser MJ, Mychasiuk R. Impulsivity and concussion in juvenile rats: examining molecular and structural aspects of the frontostriatal pathway. PLoS One. 2015;10.

202. Salberg S, Yamakawa G, Christensen J, Kolb B, Mychasiuk R. Assessment of a nutritional supplement containing resveratrol, prebiotic fiber, and omega-3 fatty acids for the prevention and treatment of mild traumatic brain injury in rats. Neuroscience. 2017;365:146-57.

203. Mychasiuk R, Hehar H, Ma I, Kolb B, Esser MJ. The development of lasting impairments: a mild pediatric brain injury alters gene expression, dendritic morphology, and synaptic connectivity in the prefrontal cortex of rats. Neuroscience. 2015;288:145-55.

204. Chung AW, Mannix R, Feldman HA, Grant PE, Im K: Longitudinal structural connectomic and rich-club analysis in adolescent mTBI reveals persistent, distributed brain alterations acutely through to one year post-injury. arXiv preprint arXiv:190908071 2019.
205. Cernak I, Chang T, Ahmed FA, Cruz MI, Vink R, Stoica B, Faden Al. Pathophysiological response to experimental diffuse brain trauma differs as a function of developmental age. Developmental neuroscience. 2010;32:442-53.

206. Huang L, Obenaus A, Hamer M, Zhang JH. Neuroprotective effect of hyperbaric oxygen therapy in a juvenile rat model of repetitive mild traumatic brain injury. Medical gas research. 2016;6:187.

207. Karve IP, Taylor JM, Crack PJ. The contribution of astrocytes and microglia to traumatic brain injury. British journal of pharmacology. 2016;173:692-702.

208. Burda JE, Bernstein AM, Sofroniew MV. Astrocyte roles in traumatic brain injury. Experimental neurology. 2016;275:305-15.

209. Clark DP, Perreau VM, Shultz SR, Brady RD, Lei E, Dixit S, Taylor JM, Beart PM, Boon WC. Inflammation in traumatic brain injury: roles for toxic A1 astrocytes and microglial-astrocytic crosstalk. Neurochemical research. 2019; 44:1410-24.

210. Chung W-S, Clarke LE, Wang GX, Stafford BK, Sher A, Chakraborty C, Joung J, Foo LC, Thompson A, Chen C. Astrocytes mediate synapse elimination through MEGF10 and MERTK pathways. Nature. 2013;504:394-400.

211. Elmore MR, Hohsfield LA, Kramár EA, Soreq L, Lee RJ, Pham ST, Najafi AR, Spangenberg EE, Wood MA, West BL. Replacement of microglia in the aged brain reverses cognitive, synaptic, and neuronal deficits in mice. Aging cell. 2018;17:e12832.

212. Bellander B-M, Lidman O, Ohlsson M, Meijer B, Piehl F, Svensson M. Genetic regulation of microglia activation, complement expression, and neurodegeneration in a rat model of traumatic brain injury. Experimental brain research. 2010;205:103-14.

213. Jonsson CA, Horneman G, Emanuelson I. Neuropsychological progress during 14 years after severe traumatic brain injury in childhood and adolescence. Brain Injury. 2004;18:921-34.

214. Ramlackhansingh AF, Brooks DJ, Greenwood RJ, Bose SK, Turkheimer FE, Kinnunen KM, Gentleman S, Heckemann RA, Gunanayagam K, Gelosa G, Sharp DJ. Inflammation after trauma: microglial activation and traumatic brain injury. Ann Neurol. 2011;70:374-83.

215. Coughlin JM, Wang Y, Minn I, Bienko N, Ambinder EB, Xu X, Peters ME, Dougherty JW, Vranesic M, Koo SM, et al. Imaging of Glial Cell Activation and White Matter Integrity in Brains of Active and Recently Retired National Football League Players. JAMA Neurol. 2017;74:67-74.

216. Ebert SE, Jensen P, Ozenne B, Armand S, Svarer C, Stenbaek DS, Moeller K, Dyssegaard A, Thomsen G, Steinmetz J, et al. Molecular imaging of neuroinflammation in patients after mild traumatic brain injury: a longitudinal (123) I-CLINDE single photon emission computed tomography study. Eur J Neurol. 2019;26:1426-32.

217. Israel I, Ohsiek A, Al-Momani E, Albert-Weissenberger C, Stetter C, Mend S, Buck AK, Kleinschnitz C, Samnick S, Siren AL. Combined [(18)F]DPA-714 micro-positron emission tomography and autoradiography imaging of microglia activation after closed head injury in mice. J Neuroinflammation. 2016;13:140

218. Wang Y, Yue X, Kiesewetter DO, Niu G, Teng G, Chen X. PET imaging of neuroinflammation in a rat traumatic brain injury model with radiolabeled TSPO ligand DPA-714. Eur J Nucl Med Mol Imaging. 2014;41:1440-9.

\section{Publisher's Note}

Springer Nature remains neutral with regard to jurisdictional claims in published maps and institutional affiliations.

Ready to submit your research? Choose BMC and benefit from:

- fast, convenient online submission

- thorough peer review by experienced researchers in your field

- rapid publication on acceptance

- support for research data, including large and complex data types

- gold Open Access which fosters wider collaboration and increased citations

- maximum visibility for your research: over $100 \mathrm{M}$ website views per year

At BMC, research is always in progress.

Learn more biomedcentral.com/submissions 